UG470

U5d

3

no.TEC-0013

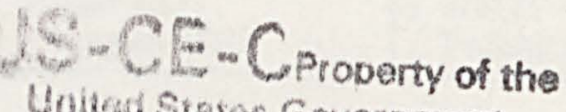

Unitod Stotes Government

\title{
Automated Classification of Basic-Level Terrain Features in Digital Elevation Models
}

US Army Corps of Engineers Topographic

Engineering Center

Linda H. Graff

August 1992

RESEARCH LIBRARY

USARMYENGINEERWATERWAYS

EXPERIMENT STATION

VICKSEUHG, MISSISSIPPI

Approved for public release; distribution is unlimited.

U.S. Army Corps of Engineers

Topographic Engineering Center

Fort Belvoir, Virginia 22060-5546 


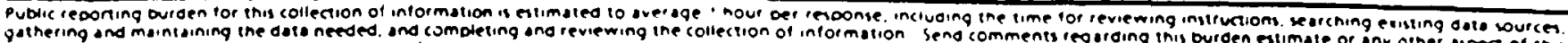

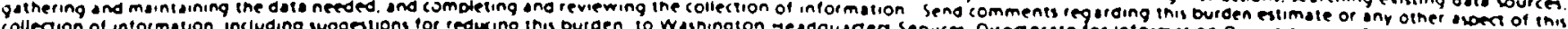

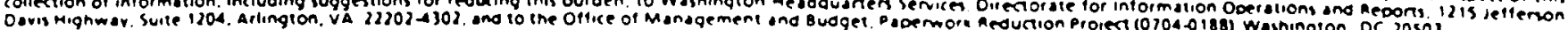

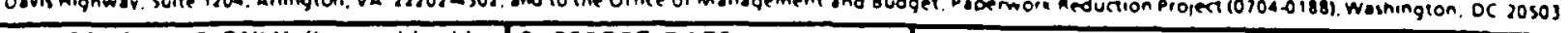

\begin{tabular}{|l|l|l}
\hline 1. AGENCY USE ONLY (Leave blank) & $\begin{array}{c}\text { 2. REPORT DATE } \\
\text { August } 1992\end{array}$ & $\begin{array}{c}\text { 3. REPORT TYPE AND DATES COVERED } \\
\text { Technical Report } \\
1 \text { Sep } 1990-31 \text { Aug } 1991\end{array}$
\end{tabular}

4. TITLE ANO SUETITLE

August 1992

5. FUNDING NUMBERS

Automated Classification of Basic-Level Terrain Features in Digital

Elevation Models

6. AUTHOR(S)

Linda H. Graff

7. PERFORMING ORGANIZATION NAME(S) ANO ADDRESS(ES)

U.S. Army Topographic Engineering Center

Fort Belvoir, VA 22060-5546

8. PERFORMING ORGANIZATION REPORT NUMBER

$4 G 470$ $45 d$

TEC-0013

9. SPONSORING/MONITORING AGENCY NAME(S) AND ADDRESS(ES)

10. SPONSORING/MONITORING

AGENCY REPORT NUMBER

11. SUPPLEMENTARY NOTES

Research for this report was completed at the U.S. Army Engineer Topographic Laboratories, which changed its name on 1 October 1991, to the U.S. Army Topographic Engineering Center.

12.. DISTRIBUTION/AVAILABILITY STATEMENT

12b. DISTRIBUTION CODE

Approved for public release; distribution is unlimited.

\section{ABSTRACT (Maximum 200 words)}

This study addresses a two-class problem in automatic terrain classification. The basic-level terrain feature selected for initial delineation is a "mount" - an aggregation of elevated features including hills, mountains, and ranges. All remaining areas are classified collectively as "non-mount." A method was developed to partition digital elevation models (DEMs) into mount and non-mount areas automatically. Then, the developed method is compared to those results obtained by a manual classification of synthetic stereo images produced from the same digital elevation data. The results of this work suggest that it may be possible to replicate the manual identification of mounts in certain physiographic regions. However, the general utility of the mount/non-mount classification approach appears to be limited by the nature of the regional terrain and by the quality of available digital data.

Terrain Analysis, Automated Terrain Classification, Terrain Reasoning, Geomorphology, Geomorphometry, Digital Elevation Data

\begin{tabular}{|l|c|c|}
\hline $\begin{array}{l}\text { 17. SECURITY CLASSIFICATION } \\
\text { OF REPORT }\end{array}$ & $\begin{array}{c}\text { 18. SECURITY CLASSIFICATION } \\
\text { OF THIS PAGE } \\
\text { UNCLLASSIFIFIED }\end{array}$ & $\begin{array}{c}\text { 19. SECURITY CLASSIFICATION } \\
\text { OF ABSTRACT } \\
\text { UNCLASSIFIED }\end{array}$ \\
\hline
\end{tabular}




\section{FIGURES}

Shaded Relief Image of Huntsville, Alabama

Shaded Relief Image of Paradise Range, California

Shaded Relief Image of Oregon, Wisconsin

Shaded Relief Image of Madison, Alabama

Shaded Relief Image of Farley, Alabama

Shaded Relief Image of West of Drinkwater

Lake, California

Files Created from the Original Elevation Data in the Preprocessing Step 
FIGURES (Continued) 


\section{TABLES}

TABLE

1

2

3

4

5

6

7

8
TITLE

PAGE

Terrain Categorization System

3

Terrain Parameters of Selected DEM Training Sites 5

Terrain Parameters of Selected DEM Test Sites

5

Statistics for Selected DEM Training Sites for All Mounts

22

Statistics for Selected DEM Training Sites for Well-Defined Mounts

22

Statistics for Selected DEM Test Sites for All Mounts

30

Statistics for Selected DEM Test Sites for Well-Defined Mounts

31

Relationship Between Sites, Physiographic Region, and

Correspondence of Automatic and Manual Classification 


\section{PREFACE}

This research was initiated under Army-sponsored, Long-Term Training at the University of Wisconsin-Madison in conjunction with graduate studies in cartography during the period September 1989 to August 1990. The research was completed at the U.S. Army Topographic Engineering Center, (TEC), (see Report Documentation Page, SF 298, Block 11, Supplementary Notes), during the period 1 September 1990 to 31 August 1991 under Army Program QG152C0B18 and submitted as a thesis in partial fulfillment of the requirements for a M.S. degree (Graff, 1991).

This research was performed under the academic supervision of Professor E. Lynn Usery. Professors Philip Muehrcke and Ralph Kiefer also served on the thesis committee. Technical supervision at TEC was provided by George E. Lukes, Chief, Autonomous Technologies Division and John V.E. Hansen, Director, Research Institute.

Mr. Walter E. Boge was Director, and Colonel Kenneth C. Kessler was Commander and Deputy Director of the U.S. Army Topographic Engineering Center at the time of publication of this report. 
called "prototypes" and are defined in part by human perception and experience. Categories range from general or superordinate, at the uppermost level, to specific or subordinate, at the bottom level.

Central to the system proposed by Rosch et al. (1976) are basic-level categories and objects. Basic-level objects are basic in perception, function, communication and knowledge organization (Lakoff, 1987).

In general, objects that are atypical or differ greatly from the prototype are more difficult to classify than those that closely resemble the category prototype (Jolicoeur et al., 1984). The classification difficulties are significant when identifying terrain features that differ greatly from the textbook examples and from each other.

In an attempt to simplify the complex and often subjective problem of terrain classification, this study employs a two-class approach to terrain classification. The basic-level terrain feature used in this study is a mount. This feature is adapted from the U.S. Geological Survey's (USGS) proposed Digital Line Graph-Enhanced (DLG-E) definition of a mount as "a landmass that projects conspicuously above its surroundings" (Guptill et al., 1990, p. A-97).

A mount is used in this study to represent elevated terrain features, such as hills, mountains and ranges. All remaining features, such as plains, basins and flats, are classified as "non-mount." The terrain classification system used in this study is shown in Table 1.

This study is guided by a divide-and-conquer philosophy. Delineation of mounts from non-mount areas as an initial two-class classification system facilitates subsequent classification of subordinate-level geomorphologic landforms. Jolicoeur defines this to be the typical pattern of categorization, i.e., basic-level identification occurs first and is followed, some time later, by subordinate- and superordinate-level identification (Jolicoeur et al., 1984).

To classify an object, one frequently employs knowledge and experience. For instance, when classifying terrain manually from aerial photographs, the boundaries between landforms are often apparent at breaks in slope that create apparent tonal and topographic changes (Mintzer and Messmore, 1984). In general, the bases of hills, as well as the tops, are more gentle in slope than the sides (Rinker, 1972). Information such as this can also be used to help delimit mount from non-mount areas in an automated classification scheme. In order to use digital data and computer capabilities to classify basic-level terrain features automatically, one must know and be able to measure the attributes associated with these features.

Geomorphometry is a subdiscipline of geomorphology that attempts to determine the geometric measures required to define and describe the landscape. Evans (1972) distinguished two subclasses of geomorphometry: general and specific. General geomorphometry is the measurement of landform characteristics over a broad continuous surface. The measures used in general geomorphometry often rely on altitude measures and derivatives of altitude, such as slope, aspect and curvature (Evans, 1972; Mark, 1975; Pike 1988). In specific geomorphometry, the measures used rely on the geometry of specific landforms, such as drumlins and cirques. However, in order for specific geomorphometry to be realized, one must isolate the form to be identified from its surroundings (Evans, 1987). This study uses geomorphometric measures of altitude, and its derivative, slope, to isolate basic-level forms from their surroundings. 
Table 1

Terrain Categorization System

Superordinate Basic $\quad$ Subordinate

$\begin{array}{lll}\text { Terrain } & \text { Mount } & \begin{array}{l}\text { Drumlin } \\ \text { Dune } \\ \text { Inselberg }\end{array} \\ & \text { Plain } & \begin{array}{l}\text { Alluvial Plain } \\ \text { Outwash Plain } \\ \text { Floodplain }\end{array} \\ & \text { Kettle } \\ & \text { Basin } & \text { Drainage Basin } \\ & \text { Sinkhole } \\ & \text { Mud Flat } \\ & \text { Tidal Flat } \\ & \text { Playa }\end{array}$

Note: This table was developed using the principles of Rosch et al. (1976).

In addition to geomorphometric measures, this research also draws upon studies that attempt to automatically delineate drainage networks and basins. These studies often reiy on the extraction of "critical points." Critical points are considered to be points that provide the maximum amount of information about a surface. Although called by different names, these points include peaks, pits, ridges, ravines, passes, slopes, break points, and flats (Peucker and Douglas, 1975).

The majority of work performed in this area uses a bottom-up aggregative approach to define features such as drainage basins and watersheds. The initial analysis frequently relies on a local operation that examines a relatively small (often a $3 \times 3$ ) neighborhood of elevation values to identify the critical points. Then, the more complex features are derived from these points. Dikau (1989) takes this approach in developing a digital geomorphological relief model (DGRM), which builds complex relief forms by combining low-level form elements and form facets.

This research combines information and methods used in manual terrain classification with automated techniques used in geomorphometry and critical point analysis to create various data layers or files. These layers are combined and analyzed to partition the input DEM into mount and non-mount areas. 


\section{METHODS}

The focus of this research is on the automated delineation of mounts using digital elevation data as the sole data source. The data used are USGS 7.5-minute-based DEMs, which correspond in coverage to 1:24,000-scale topographic maps (U.S. Geological Survey, 1990). These data have a 30-meter spacing between X and $\mathrm{Y}$ locations and are comparable in resolution to DMA DTED Level II products.

In order to design test criteria that were suitable to a wide range of terrain features, five DEM's were chosen as training sites and five DEM's as test sites. The chosen sites are located throughout the United States, they have a wide range of local relief, and they contain both well-defined and poorly defined mounts.

Well-defined mounts are considered to be those that most closely resemble the category prototype. They are often isolated, they have a definable boundary, and they possess a summit or peak. Poorly defined mounts are atypical members of the mount category and are frequently more difficult to classify.

The selected training sites are Verona, Wisconsin; Gettysburg, Pennsylvania; Huntsville, Alabama; Mustang Mountains, Arizona; and Paradise Range, California. A shaded relief image, depicting the entire DEM, is presented for each training site as it is discussed. The maximum elevation, minimum elevation, and local relief of each training site is shown in Table 2.

Verona, Wisconsin, and Gettysburg, Pennsylvania, are relatively low-relief areas of $93 \mathrm{~m}$ and $117 \mathrm{~m}$, respectively. Figure 1 depicts a shaded relief image of Verona, Wisconsin and Figure 2 shows Gettysburg, Pennsylvania. The shaded relief images of the 10 sites used in this research are portrayed with geographic north at the top of the image. Verona consists primarily of large areas of undulating hills separated by drainage divides with a few isolated, well-defined mounts. Gettysburg has an overall rolling terrain with several low-relief, isolated hills and a long linear ridge in the north-west corner.

Huntsville, Alabama, has a moderate local relief of 346 meters and several isolated, well-defined mounts with an extensive range along the eastern half of the area (Figure 3). Mustang Mountains, Arizona, has a relatively high local relief at $641 \mathrm{~m}$, and distinct, well-defined mounts. In addition to the more prevalent, well-defined conical mounts, Mustang Mountains also has several low-relief, poorly defined mounts in the southern quarter of the area (Figure 4).

Paradise Range, California, has the highest local relief at 800 meters. This area has an overall rugged topography with the majority of the mounts well-defined and large in extent (Figure 5). There are also a few small, isolated mounts scattered throughout the area. Numerous low-relief coalescing alluvial fans occupy the areas between the mounts.

The five test sites were selected using the same criteria as the training sites. These sites are Oregon, Wisconsin; Post Oak Mountains, Texas; Madison, Alabama; Farley, Alabama; and West of Drinkwater Lake, California. Table 3 shows the maximum elevation, minimum elevation, and local relief of the chosen test sites. 
TABLE 2

Terrain Parameters of Selected DEM Training Sites

\begin{tabular}{lccc}
\hline$\underline{\text { Location }}$ & Max. Elev & Min. Elev. & Local Relief \\
\hline Verona, WI & $351 \mathrm{~m}$ & $258 \mathrm{~m}$ & $93 \mathrm{~m}$ \\
Gettysburg, PA & $230 \mathrm{~m}$ & $113 \mathrm{~m}$ & $117 \mathrm{~m}$ \\
Huntsville, AL & $508 \mathrm{~m}$ & $162 \mathrm{~m}$ & $346 \mathrm{~m}$ \\
Mustang Mts., AZ & $1,966 \mathrm{~m}$ & $1,325 \mathrm{~m}$ & $641 \mathrm{~m}$ \\
Paradise Range, CA & $1,382 \mathrm{~m}$ & & $800 \mathrm{~m}$ \\
\hline
\end{tabular}

TABLE 3

Terrain Parameters of Selected DEM Test Sites

\begin{tabular}{|c|c|c|c|}
\hline Location & Max. Elev. & Min. Elev. & Local Relief \\
\hline Oregon, WI & $369 \mathrm{~m}$ & $260 \mathrm{~m}$ & $109 \mathrm{~m}$ \\
\hline Post Oak Mts., TX & $320 \mathrm{~m}$ & $179 m$ & $141 \mathrm{~m}$ \\
\hline Madison, AL & $381 \mathrm{~m}$ & $161 \mathrm{~m}$ & $220 \mathrm{~m}$ \\
\hline Farley, AL & $461 \mathrm{~m}$ & $135 \mathrm{~m}$ & $326 \mathrm{~m}$ \\
\hline $\begin{array}{l}\text { West of Drinkwater } \\
\text { Lake, CA }\end{array}$ & $1,476 \mathrm{~m}$ & $871 \mathrm{~m}$ & $605 \mathrm{~m}$ \\
\hline
\end{tabular}




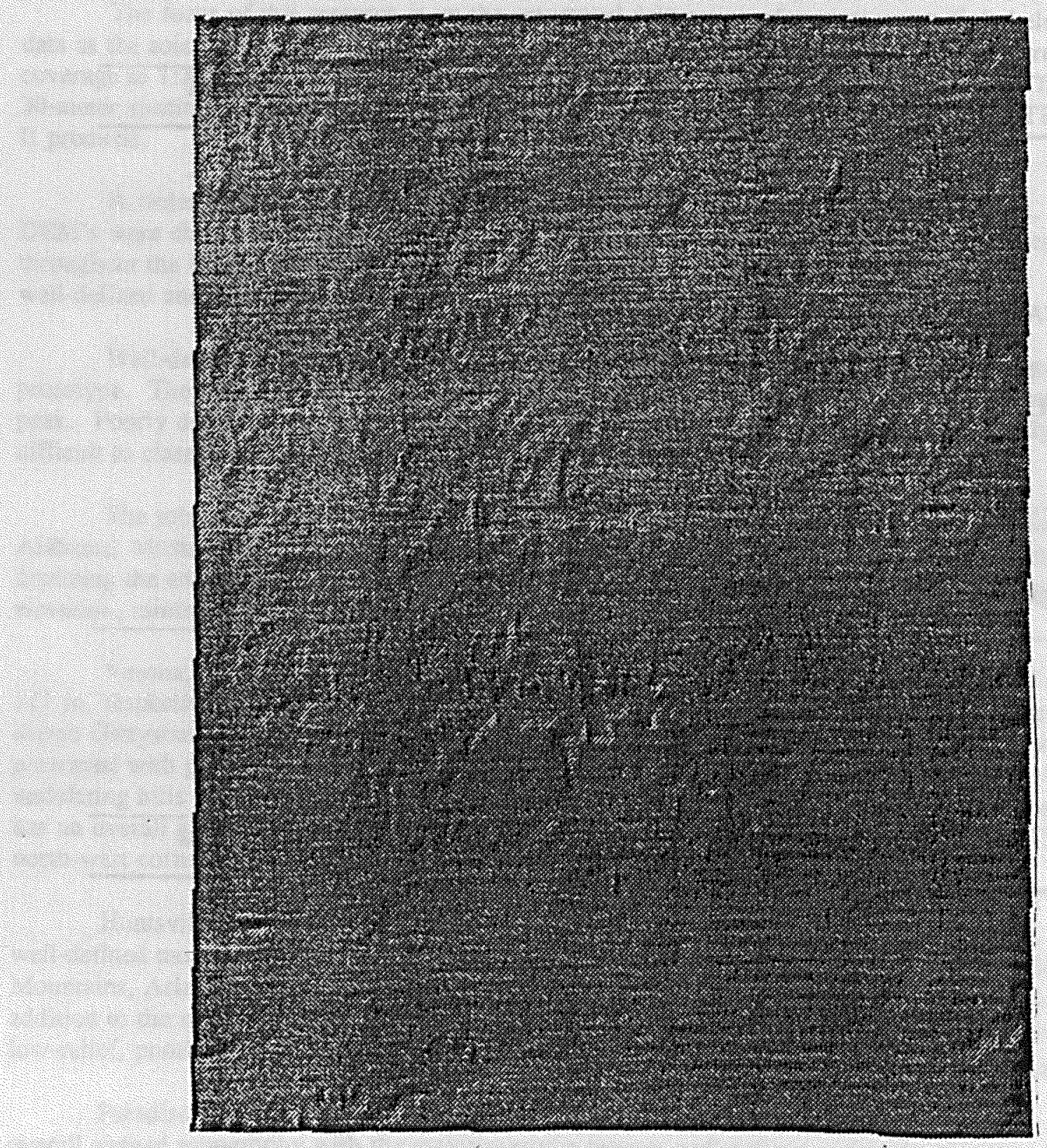

Figure 1. Shaded relief image of Verona, Wisconsin. Generated from a 7.5-minute-based digital elevation model (DEM). 


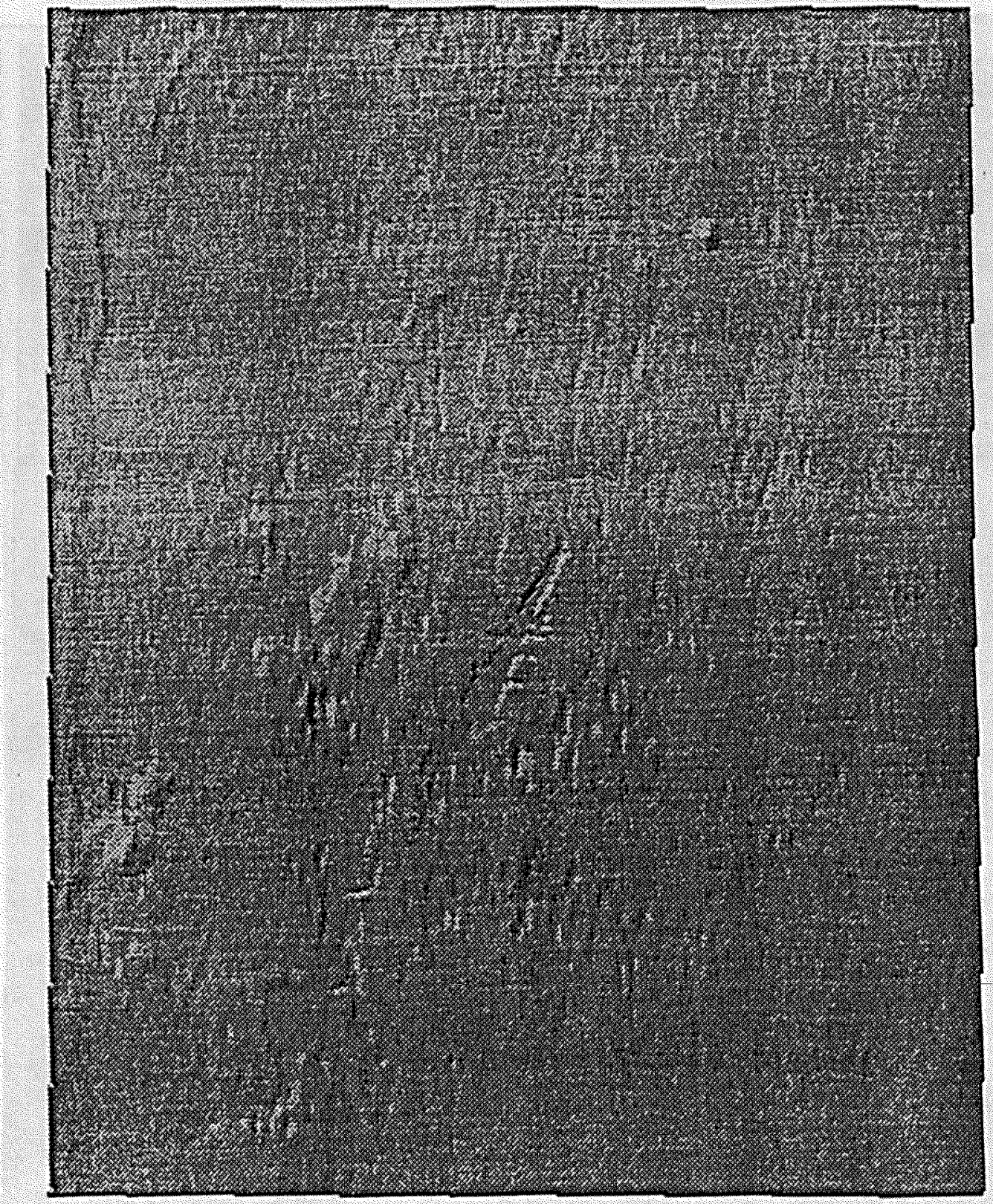

Figure 2. Shaded relief image of Gettysburg, Pennsylvania. Generated from a 7.5-minute-based digital elevation model (DEM). 


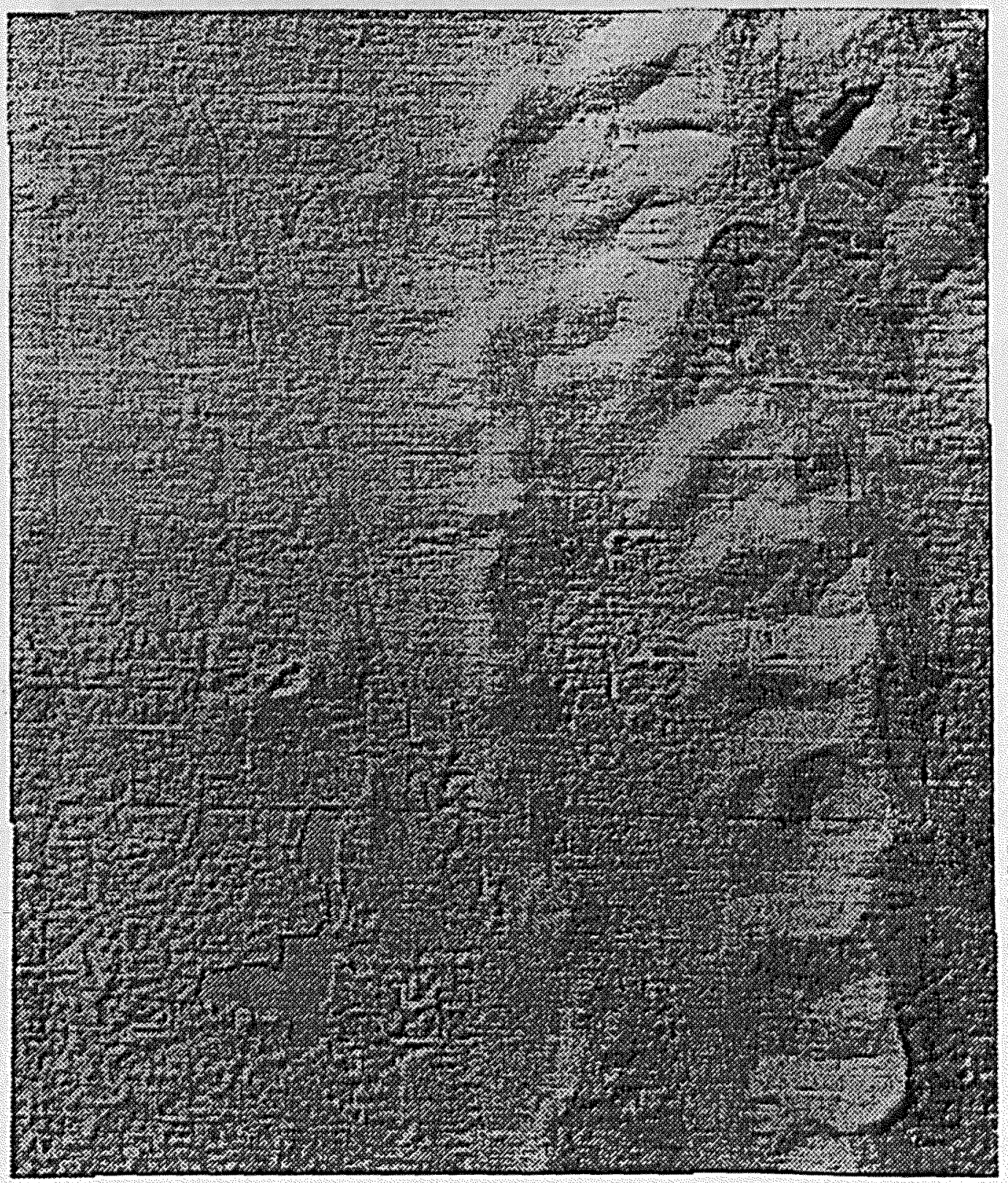

Figure 3. Shaded relief image of Huntsville, Alabama. Generated from a 7.5-minute-based digital elevation model (DEM). 


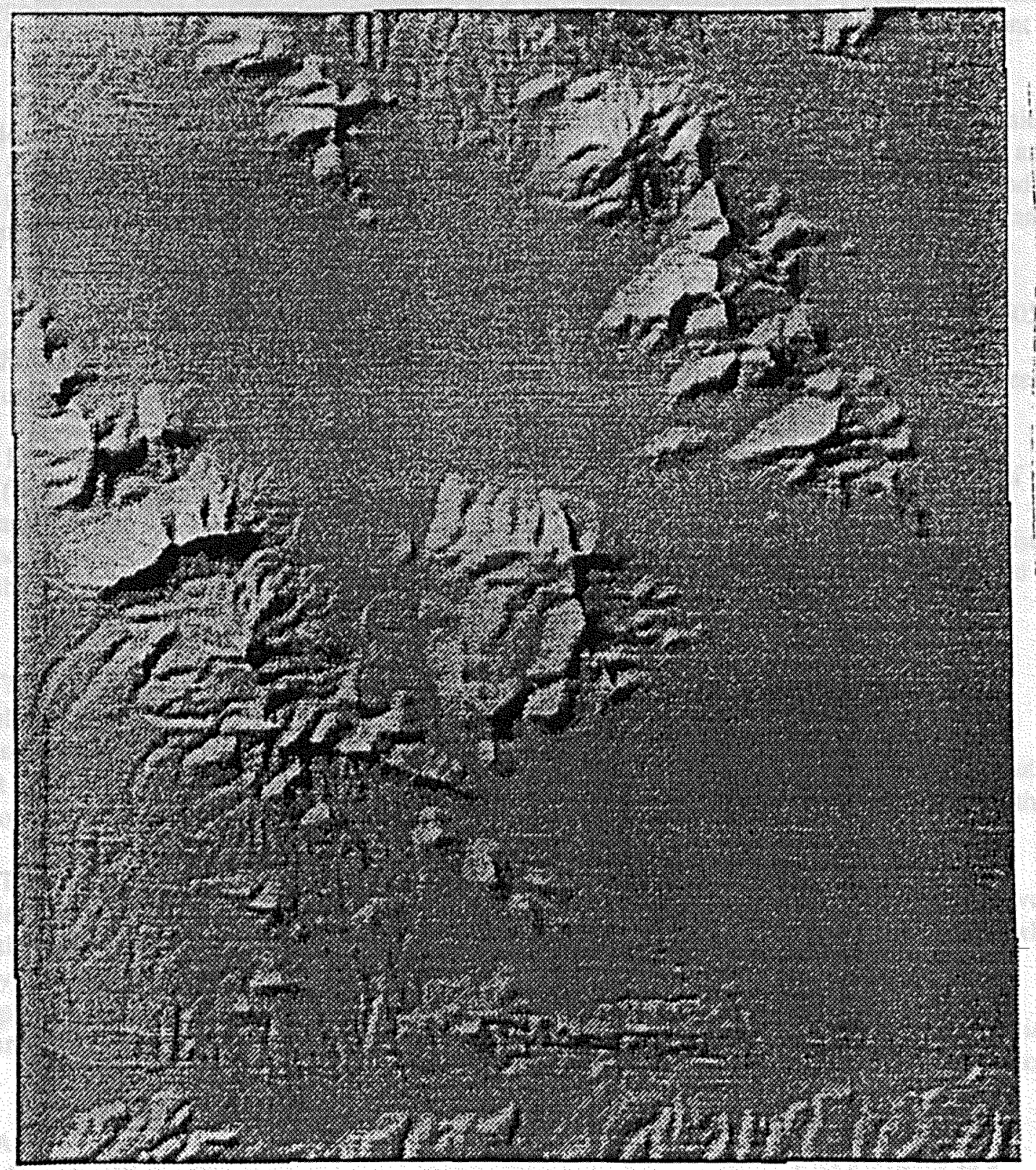

Figure 4. Shaded relief image of Mustang Mountains, Arizona. Generated from a 7.5-minute-based digital elevation model (DEM). 


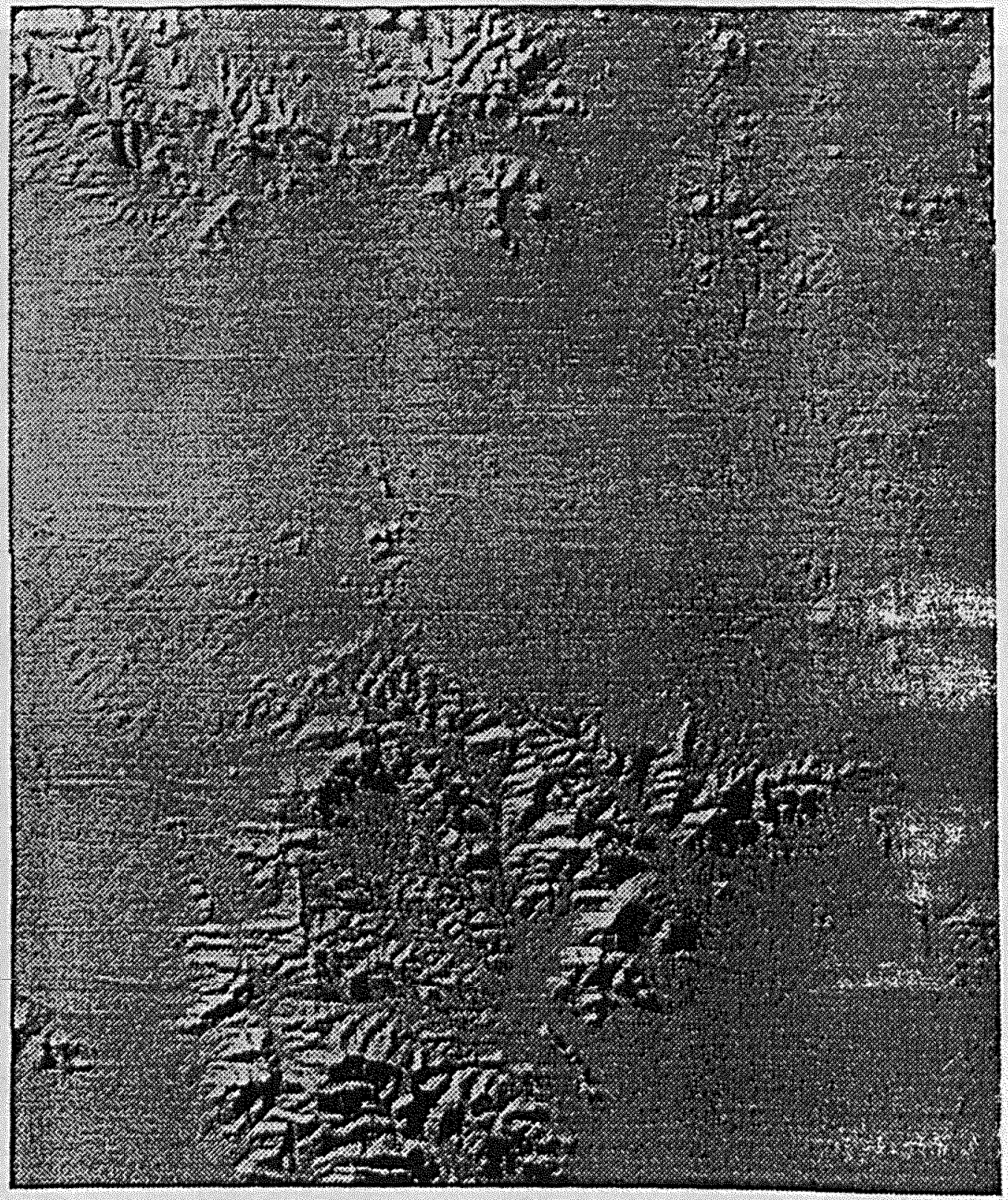

Figure 5. Shaded relief image of Paradise Range, California. Generated from a 7.5-minute-based digital elevation model (DEM). 
The lowest relief site, at $109 \mathrm{~m}$, is Oregon, Wisconsin. In addition to its low relief, this site was chosen because of its poorly defined mounts and overall rolling terrain (Figure 6). Post Oak Mountains, Texas, with a local relief of $140 \mathrm{~m}$, was chosen because it has a few isolated, low-relief, flat-topped mounts, in addition to a broad, low-relief, flat-topped range in the south-east quadrant of the DEM (Figure 7).

The Madison and Farley, Alabama, data sets have moderate local relief. The Madison site, with a local relief of $220 \mathrm{~m}$, consists of several relatively isolated, well-defined mounts and has an overall irregular topography (Figure. 8). Farley, Alabama, which has a local relief of $325 \mathrm{~m}$ and is similar to Post Oak Mountains, was chosen because it has several isolated, well-defined mounts and an extensive, relatively flat-topped range (Figure 9).

The final test site, West of Drinkwater Lake, California, has the highest local relief of 605 meters. This site combines both low- and high-relief terrain features. In addition to several well-defined "prototypical" mounts and high-relief ranges with definite peaks, this site also possesses numerous lower relief topographic features such as alluvial fans and alluvial plains (Figure 10).

In order to visualize the topography of the selected DEM's, synthetic stereo shaded relief images (Batson et al., 1976) were created using software written by scientists at the U.S. Army Topographic Engineering Center (TEC). Using red and cyan anaglyph glasses, four TEC scientists examined the synthetic stereo images. The TEC scientists were asked to identify the physical and perceptible attributes of the mounts in each area, as well as the cognitive attributes of mounts in general.

The most common responses were (1) the mounts were identifiable because they were noticeably higher in relief than the surrounding terrain; (2) the boundary between "mount" and "non-mount" was placed at a noticeable break in slope; and (3) most mounts possess a summit or peak. It was further noted that most mounts have a definable shape, and many are more rugged than the surrounding terrain.

The scientists were also asked which mounts were considered to be well-defined, which were poorly defined, and why. There tended to be overall agreement about the well-defined mounts, which were easily distinguished by their obvious peaks or summits and the sharp breaks in slope at the boundary between mount and non-mount. These most closely represent the "best examples" or "prototypes" of the mount classification. The boundary between the poorly defined mounts and the non-mount areas, on the other hand, was much more subjective and varied widely from scientist to scientist.

Also, the software that displays the stereo images enables the user to plot polygons in a graphic plane overlaying the stereo images. Prior to developing the classification method, one set of boundaries was plotted for each of the five training sites by the author. Four sets of boundaries were plotted by the scientists for all of the five test sites. In each case, the mount was identified as either well-defined or poorly defined.

The manual classifications resulted in vector polygon files depicting the boundaries between mount and non-mount areas. After performing a vector-to-raster conversion on the vector polygon files, the manually derived boundaries were overlaid with the computed data layers and the automatically classified mounts. 


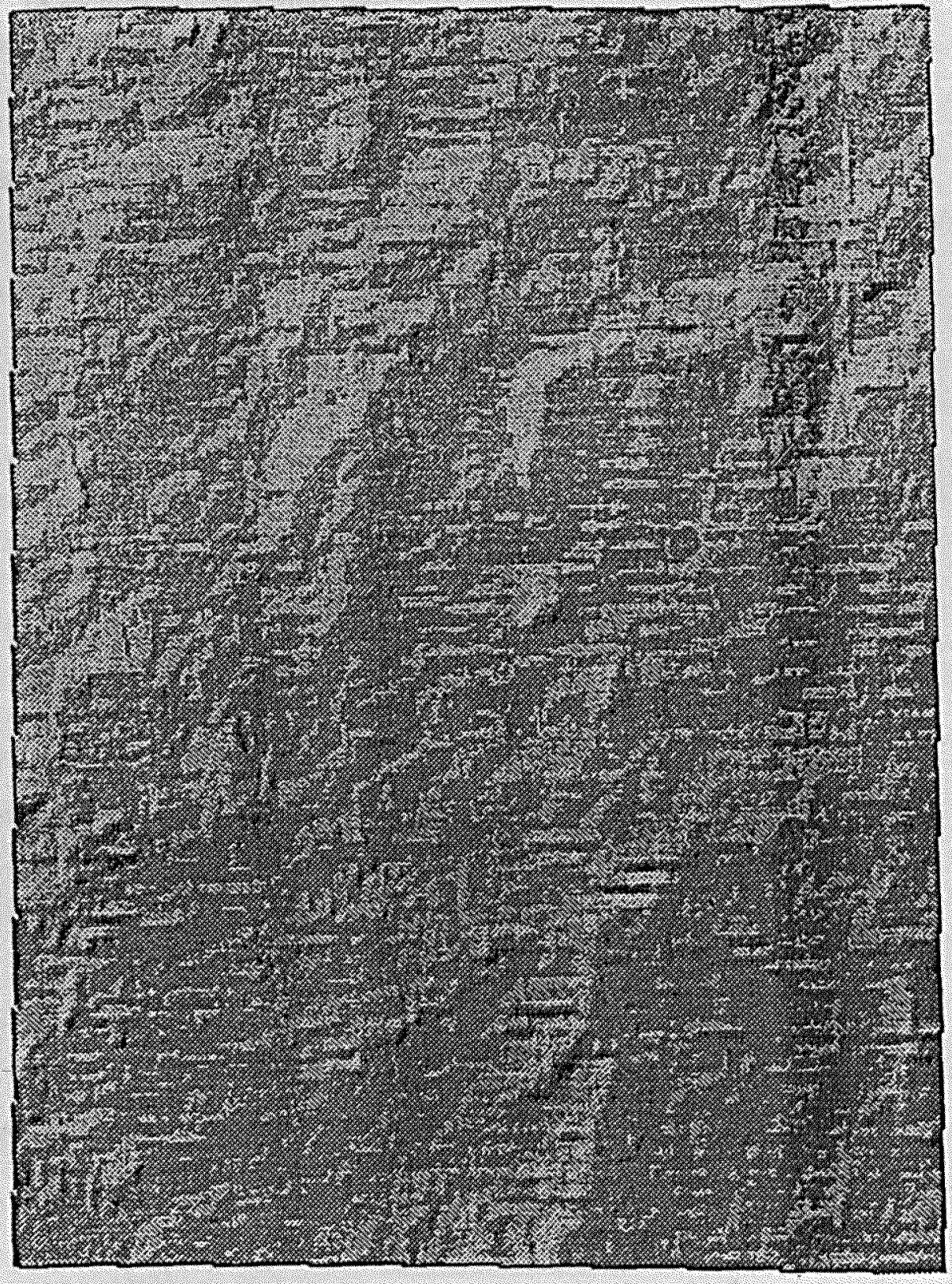

Figure 6. Shaded relief image of Oregon, Wisconsin. Generated from a 7.5-minute-based digital elevation model (DEM). 


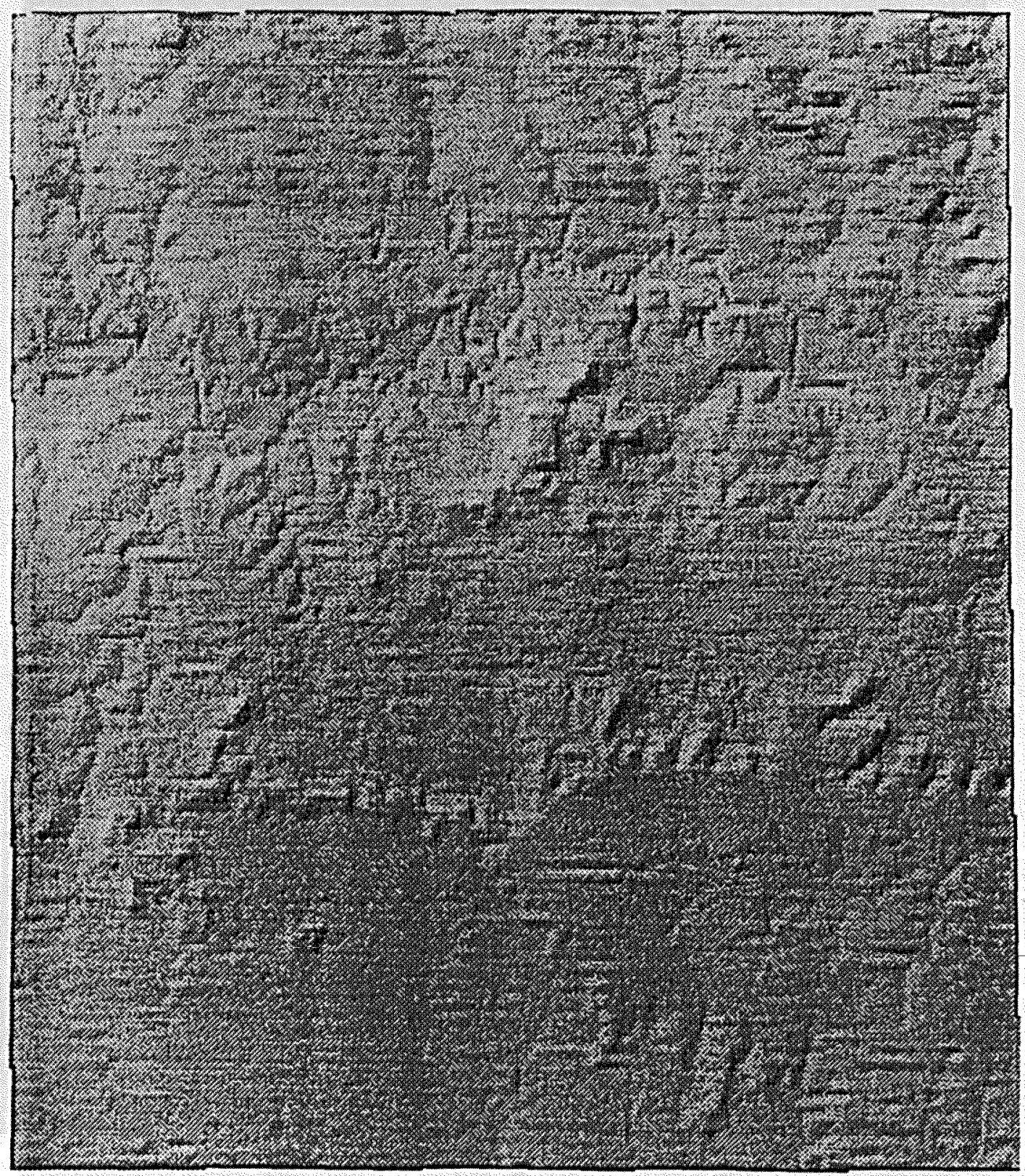

Figure 7. Shaded relief image of Post Oak Mountains, Texas. Generated from a 7.5-minute-based digital elevation model (DEM). 


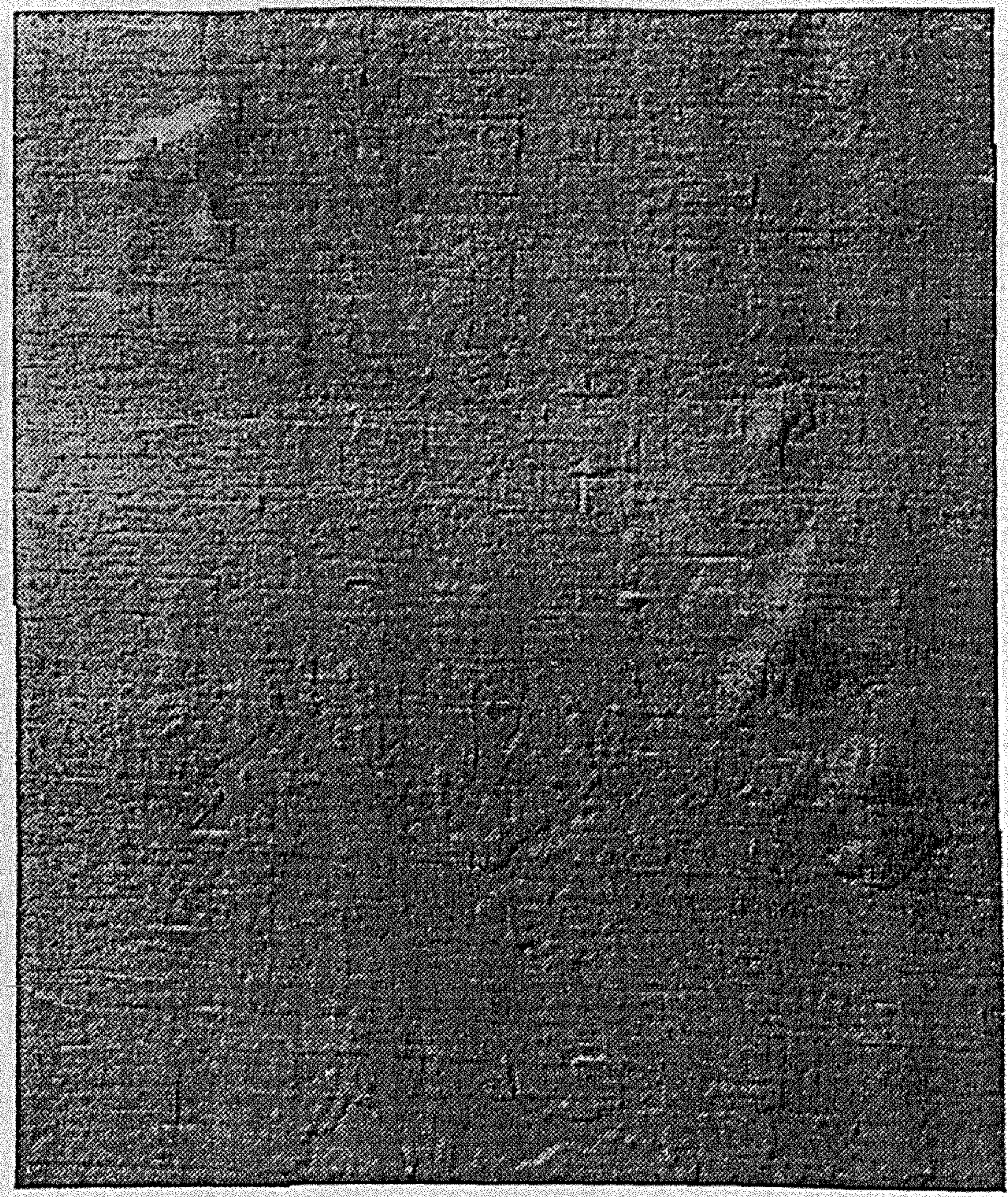

Figure 8. Shaded relief image of Madison, Alabama. Generated from a 7.5-minute-based digital elevation model (DEM). 


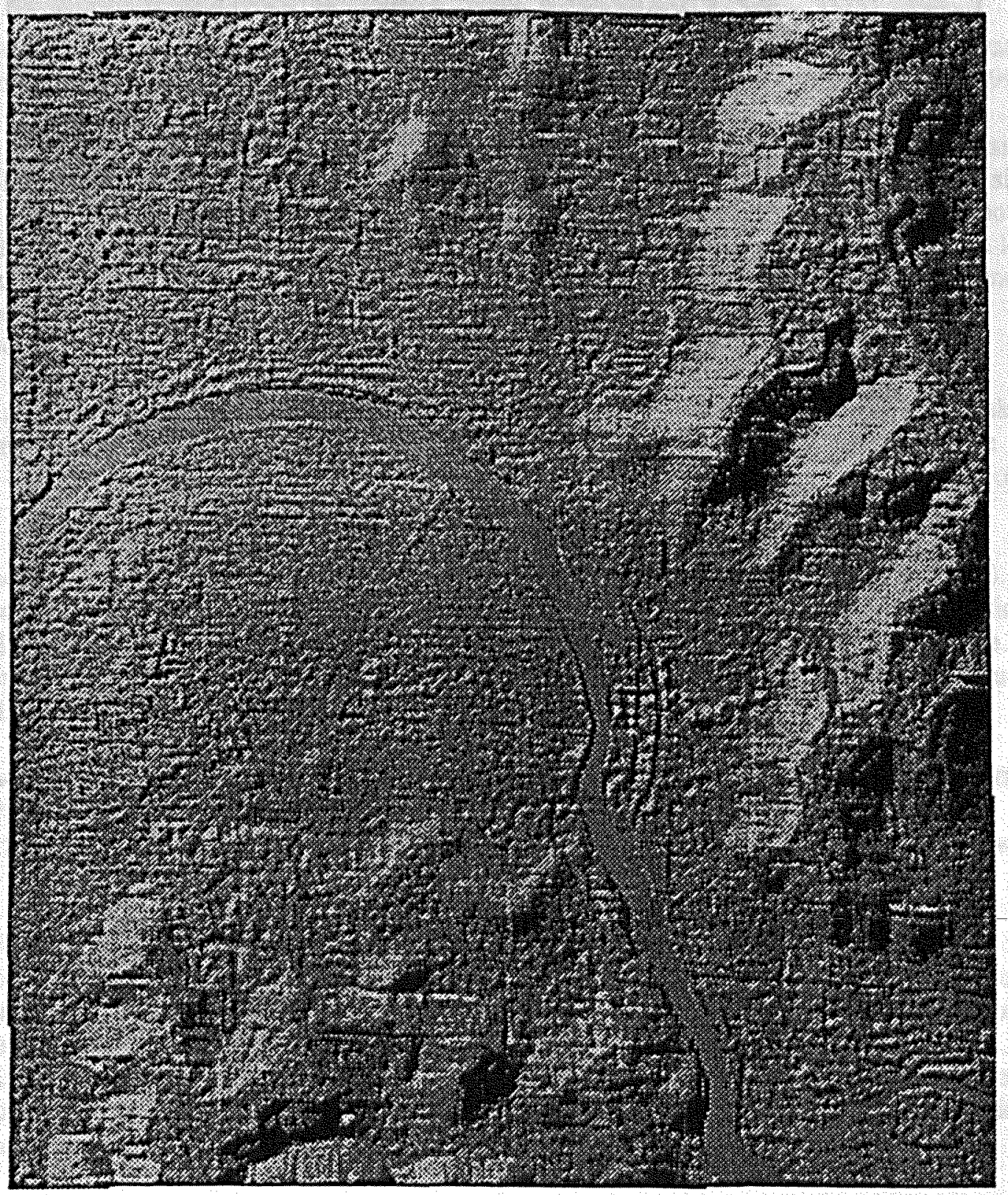

Figure 9. Shaded relief image of Farley, Alabama. Generated from a 7.5-minute-based digital elevation model (DEM). 


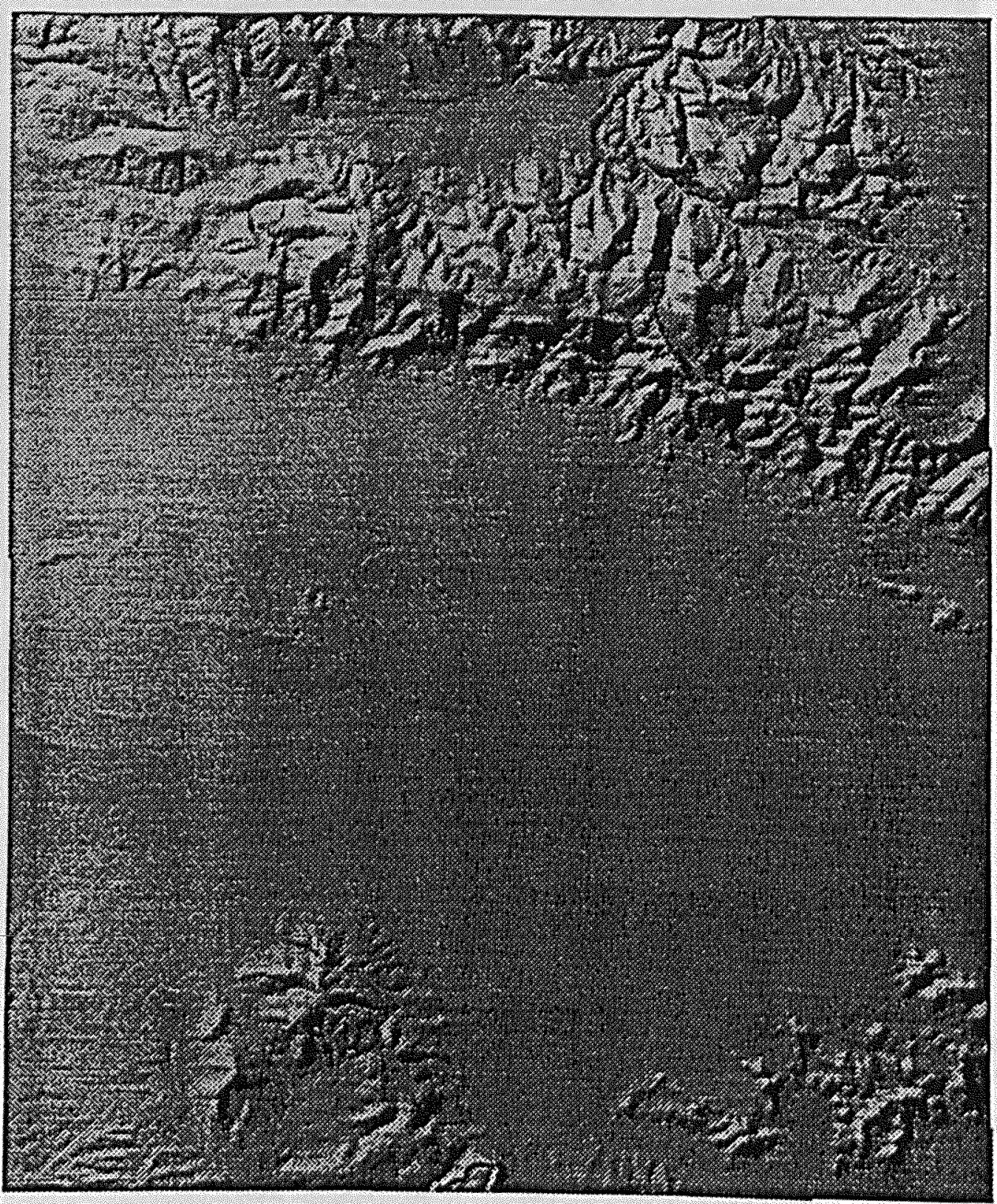

Figure 10. Shaded relief image of West of Drinkwater Lake, California. Generated from a 7.5-minute-based digital elevation model (DEM). 
The first attribute noted by the scientists was surface altitude. Since surface altitude is provided by the elevation values directly, additional attributes related to altitude were computed. These included the maximum, minimum, and median elevation, as well as the local relief of the entire area.

The second attribute noted by the scientists was slope, or gradient. A Sobel operator was used to compute the gradient of a 3 by 3 neighborhood of elevation values (Rives and Besaw, 1990).

By overlaying the manually derived boundaries with the computed slope file of a given site, it was possible to assess visually the correspondence between the two. An examination of the 10 sites shows that for those areas having a local relief of $250 \mathrm{~m}$ or greater, the slope value that corresponds most closely with the manually derived boundaries is 10 percent. However, in those areas with local relief less than $250 \mathrm{~m}$, a lower slope of 6 percent provides a closer correspondence with the manually derived boundaries. The exact dividing line between these, if indeed any really exists, requires further investigation.

In addition to slope, critical points were also computed. Critical points relate to the peak or summit attribute noted by the scientists. A simple procedure was used to find peaks, pits, ridge points and drain points. Peaks are considered to be any central point in a 3 by 3 neighborhood of values that is higher in elevation than any of its neighbors. The opposite is a pit.

The algorithm used to determine ridge and drain points was adapted from Jenson (1985). Unlike a peak, which is a local maximum compared to all eight neighbors, a ridge point is considered in this analysis to be a local maximum compared to two neighbors in either cardinal direction (e.g. higher than its north-south neighbors or higher than its east-west neighbors). The opposite is true of a drain point.

The critical points were then overlaid with the manually derived boundaries of several training sites. It was determined that, using the criteria as defined for peaks, not all mounts have an associated peak. There are also several peaks located in the non-mount areas (Figure 11A). These may result from isolated highs in the topography or errors in the data.

Because each mount did not have an associated peak, ridge points were examined in the same manner. Initially, ridge points were also computed between non-cardinal neighbors. This produced numerous ridge points, many located in areas identified as non-mount by the scientists. When only cardinal neighbors were used, the correspondence was higher than with peaks, and fewer points were identified in non-mount areas. However, there were still too many ridge points located in non-mount areas (Figure 11B). To minimize the delineation of mounts in non-mount areas, slope information was used to identify many ridge points located in areas not manually defined as mount.

Prior to extracting slope and critical points, the elevation data were smoothed twice using a 3 by 3 Gaussian smoothing mask. Previous studies using critical points show this to be the optimum number of times to smooth the data without losing excessive detail, while still removing excess noise (Seemuller, 1989).

Noise in the elevation data may result from the data collection process, both manual and automatic, or from the data source used to produce the elevation matrix. Examples of linear 


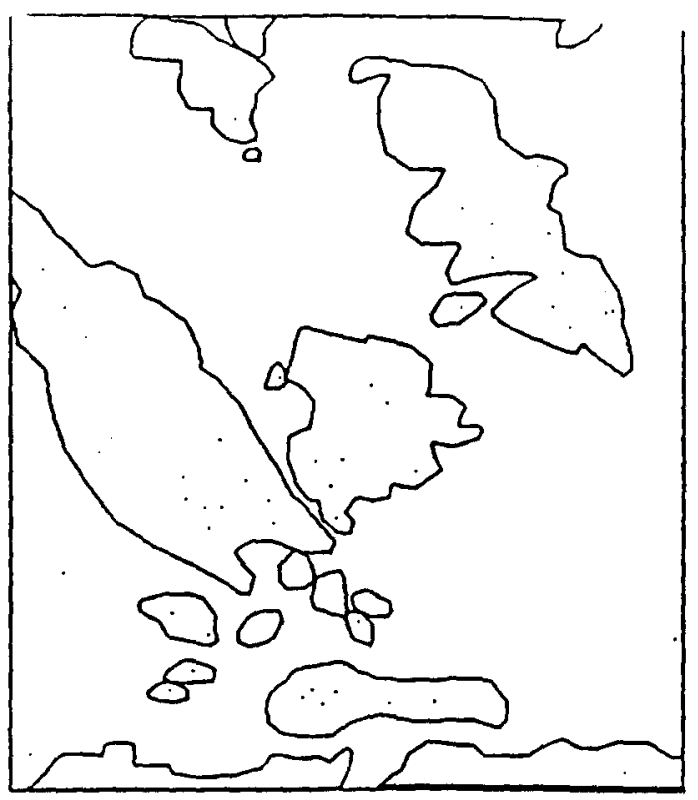

A

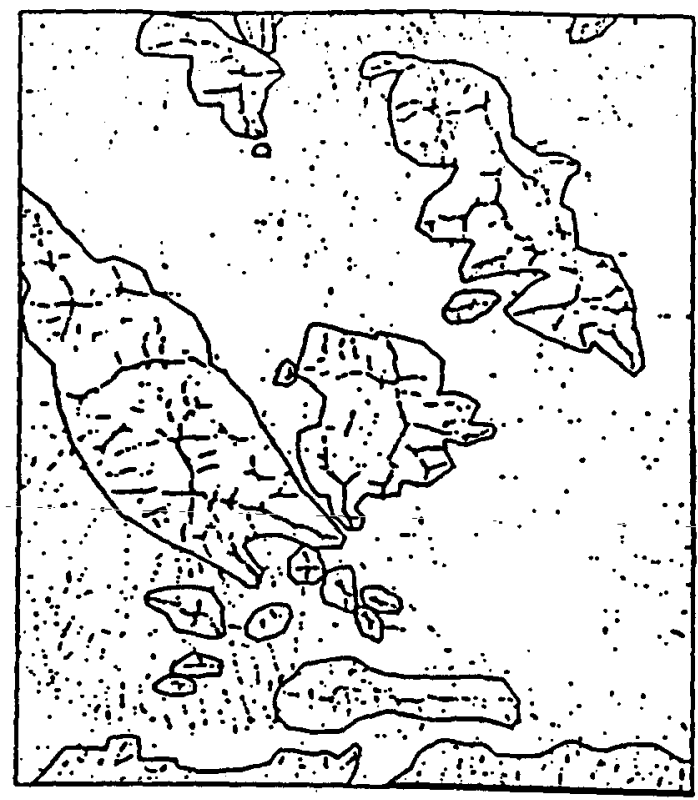

B

Figure 11. Automatically computed critical points and manually derived boundaries for Mustang Mountains, Arizona. A. Peaks and boundaries; B. Ridge points and boundaries. 
artifacts can be seen in the shaded relief images of the Gettysburg, Pennsylvania; Oregon; Wisconsin; Madison, Alabama; and Farley, Alabama sites.

To classify the mounts automatically in the input DEM's, a method was selected that uses three layers of information. Two of these layers were derived in the preprocessing step from the original elevation data and include percent slope and critical points (Figure 12). The third layer is the original elevation data file itself.

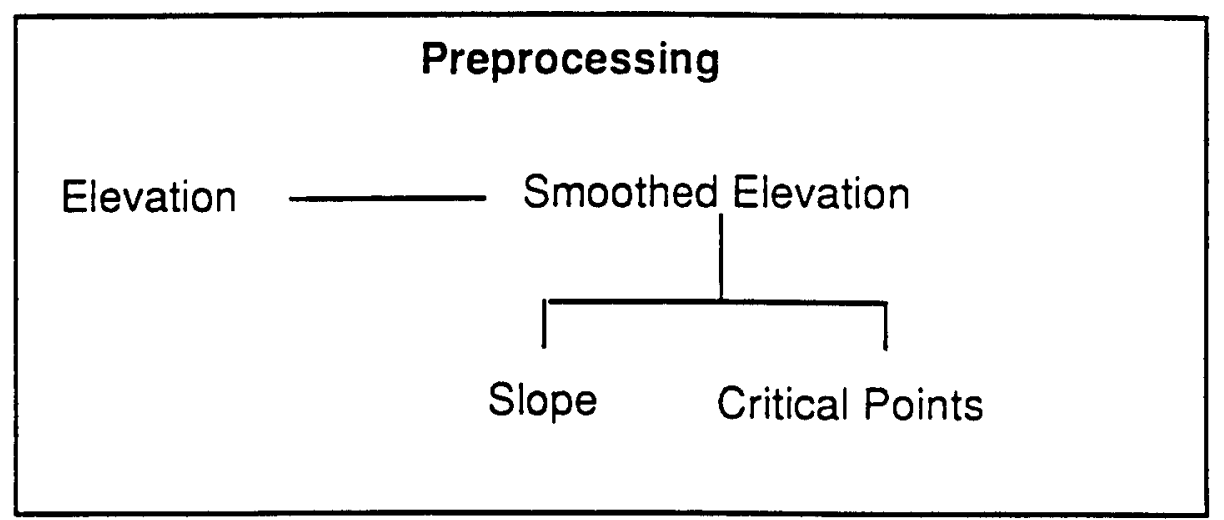

Figure 12. Files Created from the Original Elevation Data in the Preprocessing Step.

The developed method for mount classification has four steps with each step using the classification of the previous step as input (Figure 13). These steps are as follows:

1. Reclass Ridges. Assign a boundary slope between mount and non-mount areas based on local relief, and classify all ridge point locations with a slope greater than the boundary slope as mounts and all other points as non-mounts.

2. Grow to Boundary. Examine a 3 by 3 window of percent slope and mounts classified in Step 1 to "grow" the mounts from the ridge points to the boundary slope as follows: if the center of the 3 by 3 window is a non-mount and its slope is greater than the boundary slope and any of its eight neighbors are a mount, then reclassify the center as mount.

3. Grow Uphill. Continue to "grow" the mounts, classified in Step 2, by looking for uphill trends in the data. If a non-mount is encountered after an uphill trend is established, then it is reclassed as mount. The entire area is processed first from left to right, then from right to left.

4. Fill-in Flats. Apply a region-growing algorithm to a 3 by 3 window of original elevation data and mounts classified in Step 3 to fill in remaining non-mounts located in mounts. This algorithm states that if all three neighbors to any side of the center non-mount value are classed as mount and the elevation of the central value is greater than its closest mount neighbor, then reclassify the center from non-mount to mount. 
Critical Points

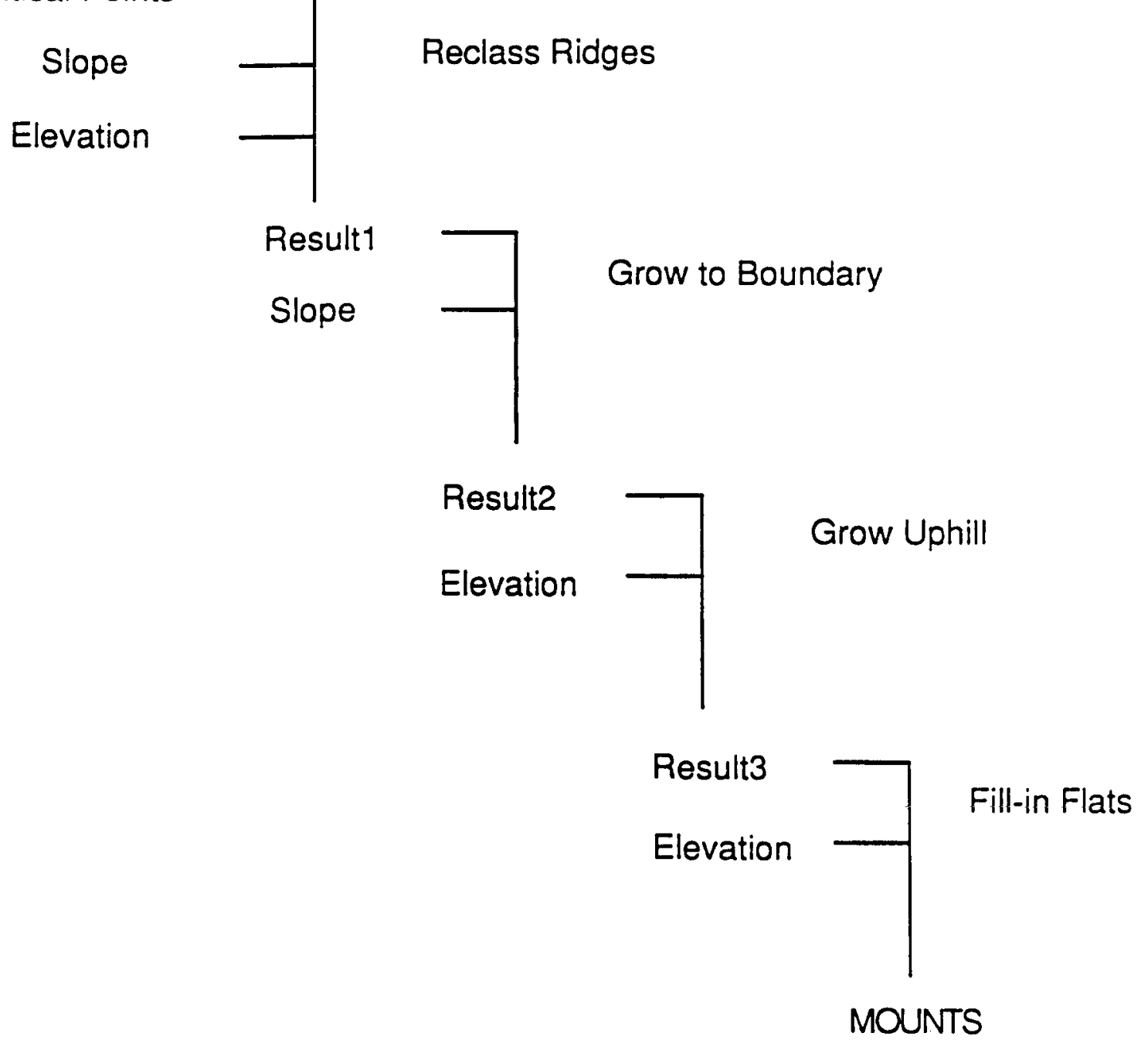

Figure 13. Steps in Automated Classification Method. 
Several routines from the Earth Resources Data Analysis System (ERDAS) were used to compare, visually and numerically, the automatic and manual classifications. Visual map comparison was performed between the automatically classified mounts and the boundaries obtained in the manual classification. The automatic classification of the five training sites was overlaid and compared to mounts manually classified by the author. The five test site results were visually compared to each of the four scientists' classification of the same site.

A visual map comparison shows noticeable differences between the manual and automated classifications. The following differences were noted: (1) some mounts that were separated manually were merged in the automated process; $(2)$ in many cases, the automated process produced more small, isolated mounts than those identified manually; and (3) the boundaries on the manually derived mounts tend to be less detailed than those derived automatically. To eliminate the small, isolated clumps, ERDAS routines were used to sieve all mounts less than 25 cells ( 5 cells $\times 5$ cells) from the final classification (Figure 14).

Numerical comparison consisted of the following: the total area (hectares) of all mounts as determined automatically and manually; the total area of all mounts determined to be well-defined manually compared to similar mounts determined automatically; and the application of the coefficient of areal correspondence, which evaluates the correspondence between areal patterns (Unwin, 1981).

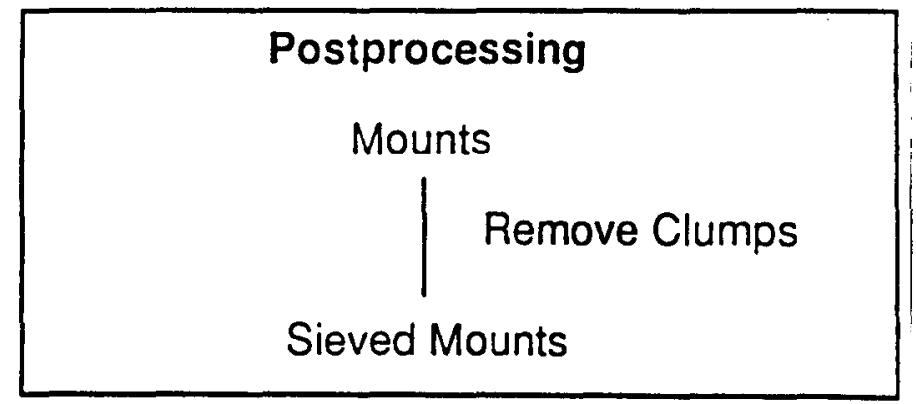

Figure 14. Postprocessing Removal of Small, Isolated Clumps.

\section{RESULTS}

\section{Training Sites}

Visual comparison of the mount file shows that, in each case, the well-defined mounts that were identified manually were also identified automatically, with the closest overlap appearing in the high-relief areas. In general, the correspondence is much lower where the mounts are poorly defined. This can be seen in the figures that follow where a more detailed analysis is provided.

A numerical comparison of all training sites shows an overall coefficient of areal correspondences that ranges from a low of 0.26 to a high of 0.81 (Table 4). As would be expected, the sites with a large percentage of well-defined mounts produce higher correspondences than those with a small percentage. In general, those sites with greater local relief also produce higher correspondences, both overall and well-defined, than do the sites with lower local relief (Tables 4 and 5). 
Table 4.

Statistics for Selected DEM Training Sites for ALL MOUNTS

\begin{tabular}{lrcl}
\hline Location & \multicolumn{2}{c}{ Area of Mounts } & \multicolumn{1}{c}{$\mathrm{Ca}^{2}$} \\
& $\underline{\text { Auto }}$ & $\underline{\text { Manual }}$ & \\
\hline Verona, WI & 5,843 & 7,198 & .65 \\
Gettysburg, PA & 699 & 576 & .26 \\
Huntsville, AL & 6,038 & 5,781 & .81 \\
Mustang Mts., AZ & 5,143 & 5,063 & .74 \\
Paradise Range, CA & 5,195 & 5,387 & .81 \\
\hline
\end{tabular}

${ }^{1}$ Area in hectares.

${ }^{2} \mathrm{Ca}=$ coefficient of areal correspondence.

Table 5.

Statistics for Selected DEM Training Sites for WELL DEFINED MOUNTS

Location Area of Mounts ${ }^{1}$

$\mathrm{Ca}^{2}$

Auto Manual

Verona, WI

$5,228 \quad 6,575$

.68

Gettysburg, PA

$125 \quad 95$

.58

Huntsville, AL

$5,483 \quad 5,625$

.87

Mustang Mts., AZ

$4,286 \quad 3,979$

.83

Paradise Range, CA

$4,660 \quad 4,898$

.82

'Area in hectares.

${ }^{2} \mathrm{Ca}=$ coefficient of areal correspondence. 
An analysis of Verona, Wisconsin, the site with the lowest local relief, shows an overall correspondence of 0.65 (Table 4). This is a fairly high correspondence for such a low-relief area. However, as can be seen in Figure 15, 91 percent of the total area of the mounts identified manually was considered to be well-defined, which accounts for this high value. Examination of the well-defined mounts raised the correspondence by only 0.03 to a value of 0.68 (Table 5).

The site at Gettysburg, Pennsylvania, with its rolling terrain, linear ridges, and few isolated, well-defined mounts, produced the lowest overall correspondence, 0.26 (Table 4). One reason for this very low value is that a ridge that was quite obvious in the manual identification was totally missed in the automatic classification (Figure 16). This ridge does not possess the required ridge points with slope greater than the boundary class in order for it to be extracted. Consequently, other criteria are required to extract automatically a feature such as this.

This low overall correspondence is not surprising because only 16 percent of the area of the manually defined mounts was considered to be well-defined (Figure 16). The correspondence more than doubled to 0.58 when only the well-defined mounts were considered. This increase in correspondence suggests that the automatic procedures classified more locations as mount than were classified manually.

Fairly high overall correspondences were obtained for the remaining sites -- Huntsville, Alabama; Mustang Mountains, Arizona; and Paradise Range, California (Table 4). Mustang Mountains was the lowest of the three at 0.74 , and both Huntsville and Paradise Range had a value of 0.81 .

Huntsville, Alabama, with a moderate local relief, produced overall results comparable to those of the highest relief site (Table 4). The correspondence, when only well-defined mounts were considered, was 0.87 , which is the highest for any of the training sites (Table 5). This suggests that local relief does not affect the results as much as the percent of well-defined mounts in the area. Ninety-seven percent of the total area of mounts classified automatically were considered to be well-defined, which is the highest for any of the training sites (Figure 17).

The Mustang Mountains, Arizona, site has an overall correspondence of 0.74 (Table 4). This is less than the lower relief site of Huntsville because Mustang Mountains has a greater percentage of poorly defined mounts (Figure 18). The percent of total area of mounts-considered to be well-defined was 83 percent for Mustang Mountains and 97 percent for Huntsville. Most of the poorly defined mounts are located in the southern quarter of the area where the mounts have lower relief and the boundaries are less distinct. The correspondence rose to 0.83 when only the well-defined mounts were considered (Table 5).

Paradise Range, California, is the training site with the highest local relief. The overall correspondence is high at 0.81 which is equivalent to that of Huntsville (Table 4). Ninety-one percent of the total area of all mounts classified automatically were considered to be well-defined by the scientists (Figure 19). As would be expected, the correspondence also is high, 0.82 , when only the well-defined mounts are considered (Table 5). 


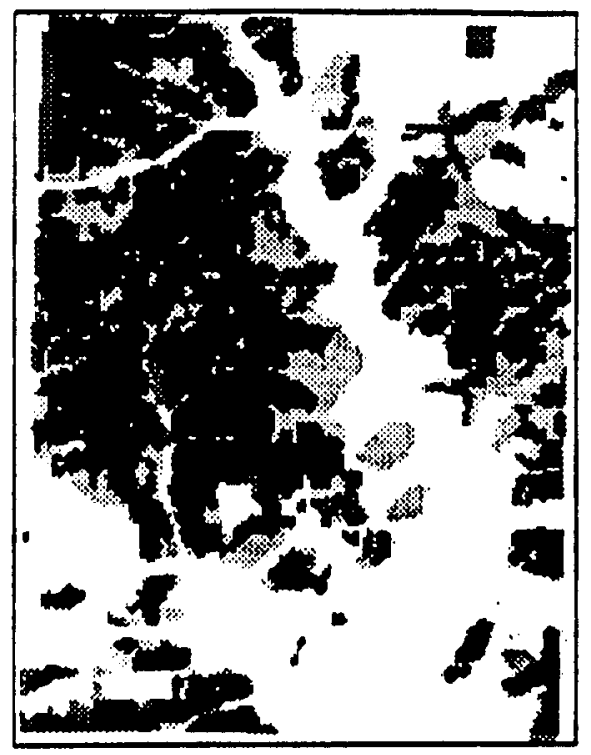

A

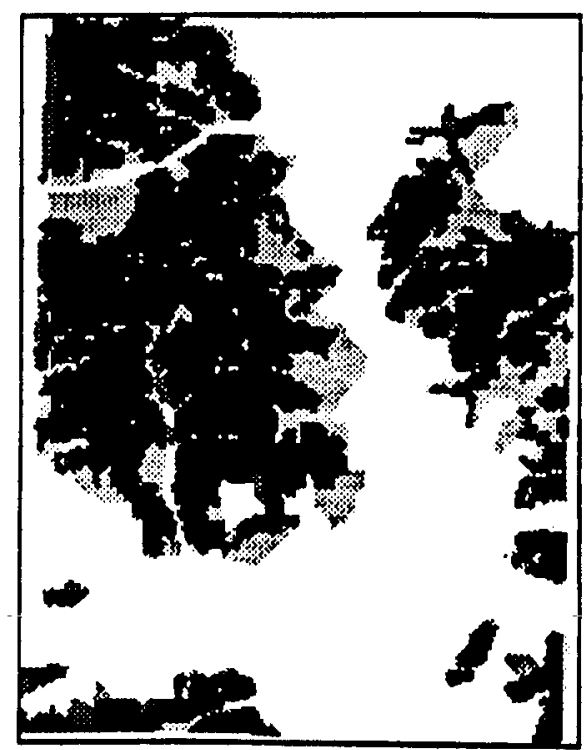

B

Figure 15. Correspondence between manually and automatically classified mounts for Verona, Wisconsin. Manually classified mounts are in light gray, automatically classified mounts are in medium gray, and overlap is in dark gray. A. All mounts; B. Well-defined mounts only. 


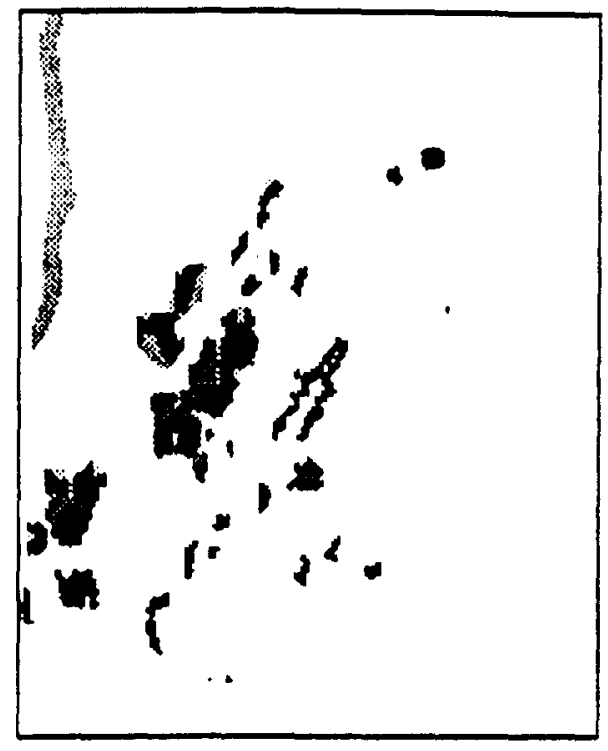

A

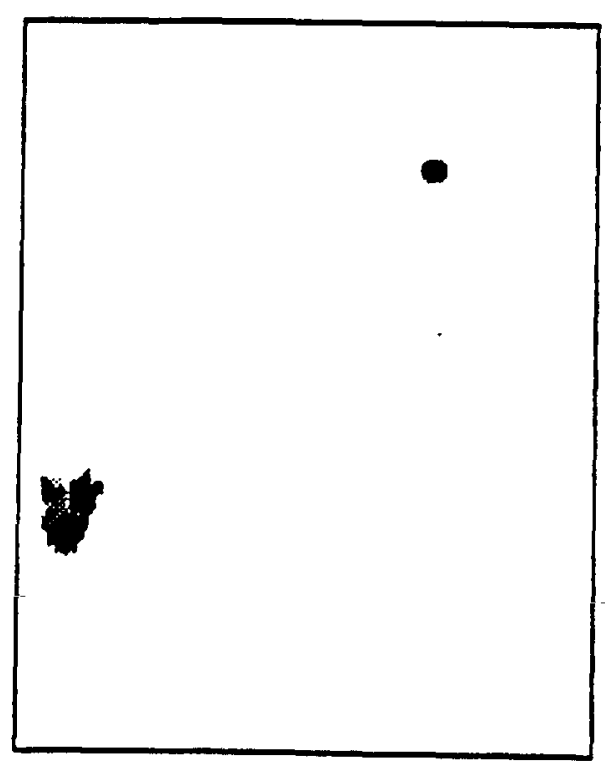

B

Figure 16. Correspondence between manually and automatically classified mounts for Gettysburg, Pennsylvania. Manually classified mounts are in light gray, automatically classified mounts are in medium gray, and overlap is in dark gray. A. All mounts; B. Well-defined mounts only. 


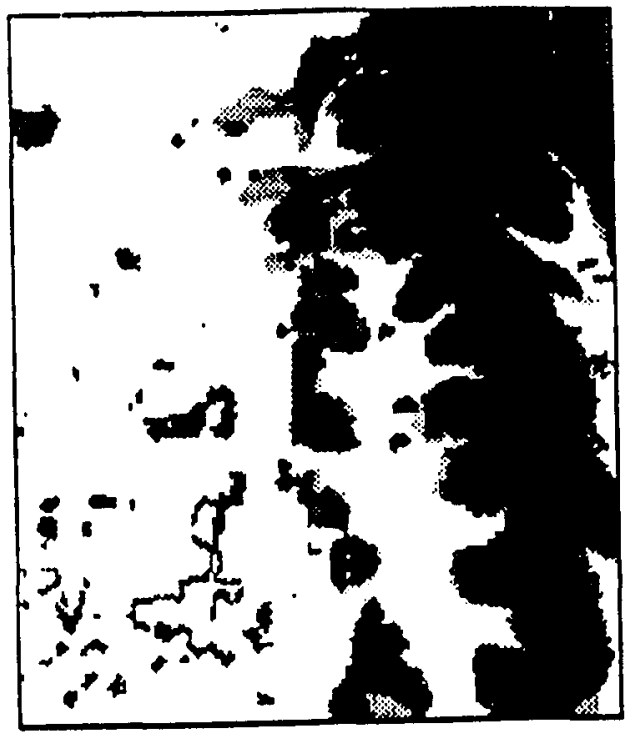

A

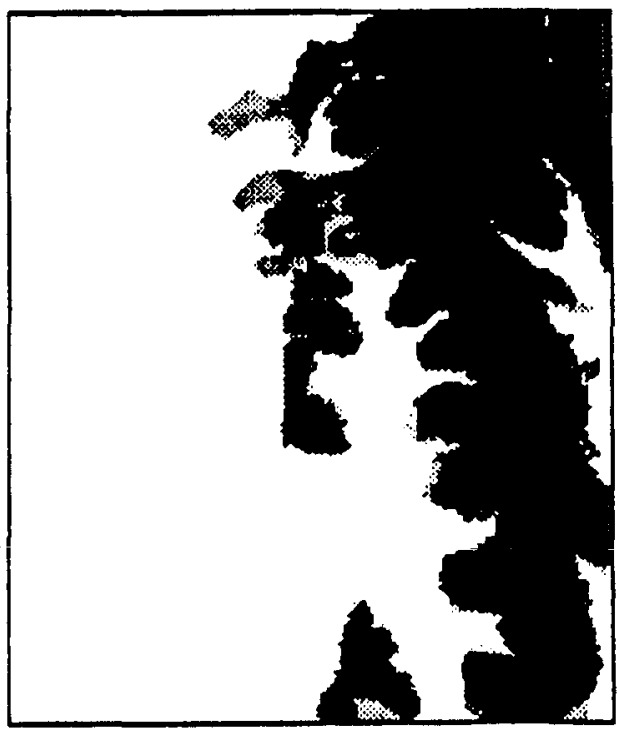

B

Figure 17. Correspondence between manually and automatically classified mounts for Huntsville, Alabama. Manually classified mounts are in light gray, automatically classified mounts are in medium gray, and overlap is in dark gray. A. All mounts; B. Well-defined mounts only. 


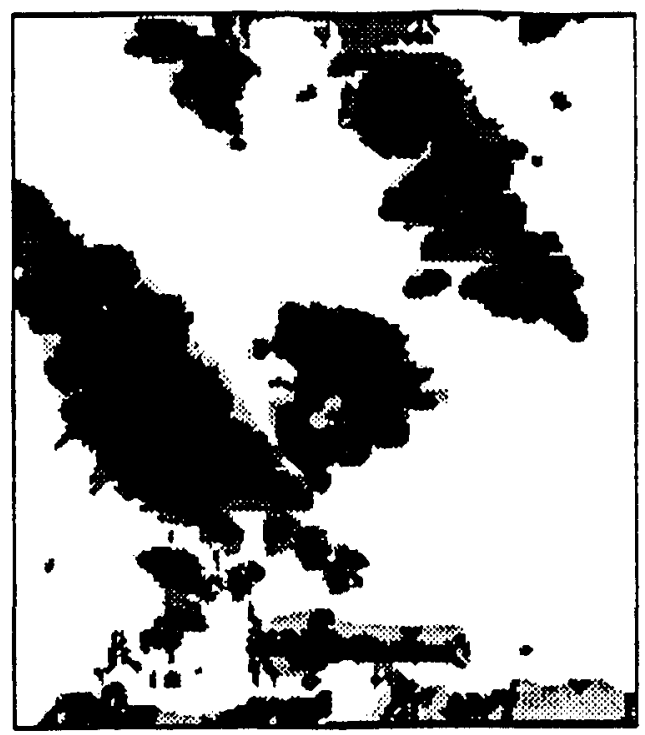

A

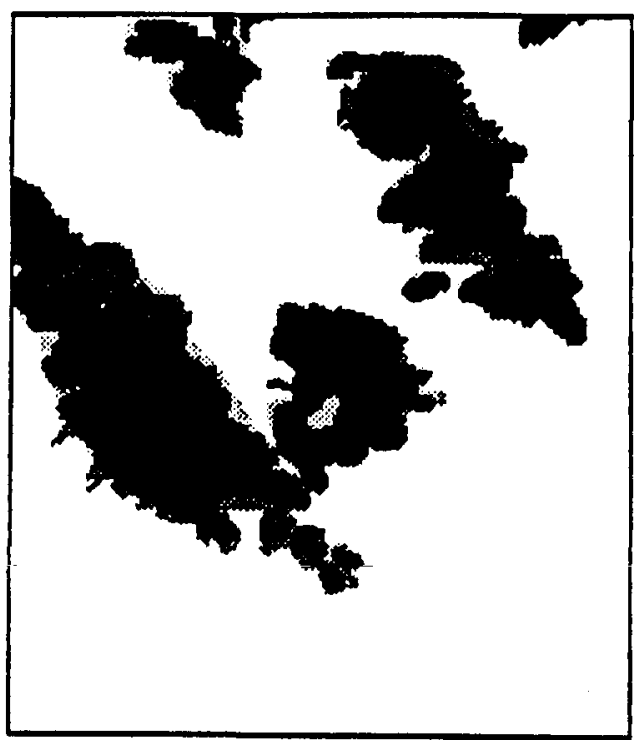

B

Figure 18. Correspondence between manually and automatically classified mounts for Mustang Mountains, Arizona. Manually classified mounts are in light gray, automatically classified mounts are in medium gray, and overlap is in dark gray. A. All mounts; B. Well-defined mounts only. 


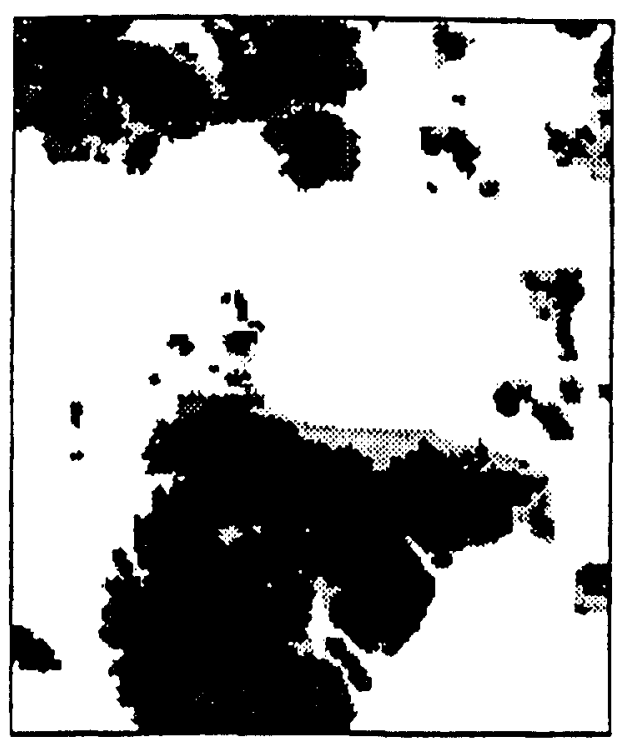

A

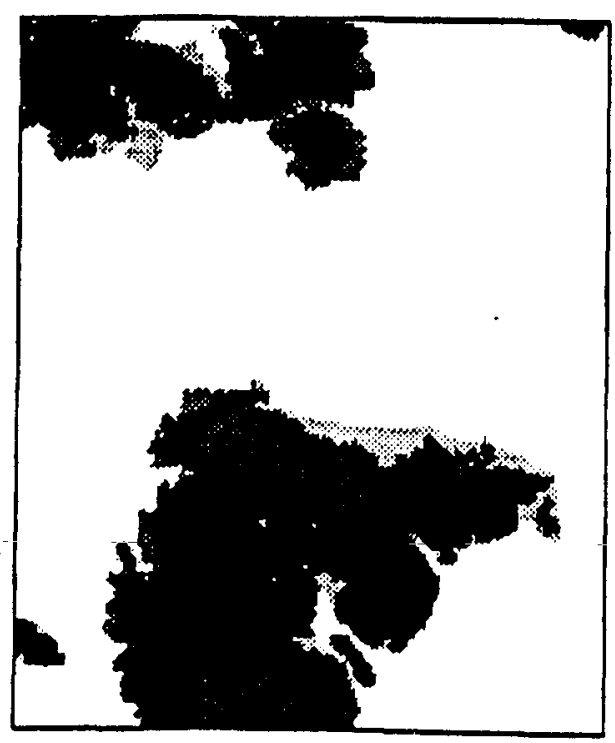

B

Figure 19. Correspondence between manually and automatically classified mounts for Paradise Range, California. Manually classified mounts are in light gray, automatically classified mounts are in medium gray, and overlap is in dark gray. A. All mounts; B. Well-defined mounts only. 


\section{Test Sites}

There is general agreement among the four TEC scientists over which areas in the DEM are considered to be mounts. In all cases containing well-defined, or "prototypical", mounts, the correspondence between the scientists is readily apparent. However, where the mounts are poorly defined and less obvious, the determination of their location and extent is much more subjective and varies considerably from scientist to scientist.

The results of the test sites substantiate those found in the training sites. Visually, there appears to be a high correspondence with the well-defined mounts and a much lower correspondence with the poorly defined mounts, especially in the high-relief areas.

The coefficient of areal correspondence further supports the findings of the visual comparison. As can be seen in Tables 6 and 7, the overall correspondences are better in higher relief areas; however, the overall correspondences also vary widely from scientist to scientist. The correspondences of the well-defined mounts are fairly consistent for the three low-relief sites: Oregon, Wisconsin; Post Oak Mountains, Texas; and Madison, Alabama. The well-defined correspondences are much greater for the two higher relief areas of Farley, Alabama, and West of Drinkwater Lake, California.

The lowest relief site, Oregon, Wisconsin, shows overall correspondences that range between scientists from 0.38 to 0.52 (Table 6). These are relatively high correspondences considering much of the area is irregular or undulating, and very few of the mounts were considered to be well-defined (in many instances only certain boundaries of a particular mount were considered by the scientists to be well-defined) (Figures 20 and 21). The correspondences did not improve dramatically when only the well-defined mounts were considered (Table 7). This is because it is much more difficult to establish a boundary between mount and non-mount in low-relief areas, even if the mounts are considered to be well-defined.

The Post Oak Mountains, Texas, site shows the lowest overall correspondences and the lowest correspondences of well-defined mounts (Tables 6 and 7). In addition to its low relief, another factor that contributes to the low correspondences is the inability of the algorithms to deal with the large flat-topped range in the south-east quadrant of the site. The boundary between the range and the non-mount area visually matches in both the manual and automated identifications; however, only 1,581 hectares were identified automatically, while the manual classifications ranged from 2,667 to 3,186 hectares (Figures 22 and 23 ). The problem lies in filling in the flat-top using the automated method. This is an issue that requires further investigation.

The Madison, Alabama, site has a moderate local relief and shows low overall correspondences for all four scientists; however, it was under 0.2 for two of the test subjects (table 6). Like the other low-relief sites, this area has a few isolated, well-defined mounts with an overall irregular topography. The correspondences increased, and more than doubled in some cases, when only the well-defined mounts were considered (Table 7 and Figures 24 and 25).

Relatively high correspondences, both for all mounts and well-defined mounts only, were obtained from the Farley, Alabama, site (Tables 6 and 7). This largely results from the fact that most of the mounts extracted manually are considered to be well-defined. Like Post Oak Mountains, this site has a large, relatively flat-topped range along its eastern side. However, because the flat area on 
Table 6

Statistics for Selected DEM Test Sites for ALL Mounts

\begin{tabular}{|c|c|c|c|c|c|}
\hline Location & Aute & Scientist 1 & Scientist2 & $\underline{\text { Scientist } 3}$ & Scientist4 \\
\hline \multicolumn{6}{|l|}{ Oregon, WI } \\
\hline $\begin{array}{l}\text { Total Area } \\
\mathrm{Ca}^{2}\end{array}$ & 3,386 & $\begin{array}{c}7,423 \\
.38\end{array}$ & $\begin{array}{c}5,915 \\
.40\end{array}$ & $\begin{array}{c}4,693 \\
.52\end{array}$ & $\begin{array}{c}6,197 \\
.41\end{array}$ \\
\hline \multicolumn{6}{|c|}{ Post Oak Mts. TX } \\
\hline $\begin{array}{l}\text { Total Area } \\
\mathrm{Ca}\end{array}$ & 5,738 & $\begin{array}{c}9,817 \\
.38\end{array}$ & $\begin{array}{c}12,493 \\
.38\end{array}$ & $\begin{array}{c}5,275 \\
.37\end{array}$ & $\begin{array}{c}4,148 \\
.37\end{array}$ \\
\hline \multicolumn{6}{|l|}{ Madison. $\mathrm{AL}$} \\
\hline $\begin{array}{l}\text { Total Area } \\
\mathrm{Ca}\end{array}$ & 1,793 & $\begin{array}{c}8,322 \\
.18\end{array}$ & $\begin{array}{c}7,333 \\
.19\end{array}$ & $\begin{array}{c}3,701 \\
.36\end{array}$ & $\begin{array}{c}4,060 \\
.38\end{array}$ \\
\hline \multicolumn{6}{|l|}{ Farley AL. } \\
\hline $\begin{array}{l}\text { Total Area } \\
\mathrm{Ca}\end{array}$ & 6,491 & $\begin{array}{c}7,533 \\
.70\end{array}$ & $\begin{array}{c}7,465 \\
.63\end{array}$ & $\begin{array}{c}6,694 \\
.75\end{array}$ & $\begin{array}{c}6,987 \\
.72\end{array}$ \\
\hline \multicolumn{6}{|c|}{ West of Drinkwater Lake. CA } \\
\hline $\begin{array}{l}\text { Total Area } \\
\mathrm{Ca}\end{array}$ & 5,738 & $\begin{array}{c}10,672 \\
.44\end{array}$ & $\begin{array}{c}8,325 \\
.58\end{array}$ & $\begin{array}{c}7,740 \\
.66\end{array}$ & $\begin{array}{c}7,540 \\
.71\end{array}$ \\
\hline
\end{tabular}

Area in hectares.

${ }^{2} \mathrm{Ca}=$ coefficient of areal correspondence. 
Table 7

Statistics for Selected DEM Test Sites for WELL DEFINED Mounts

Location $\quad$ Auto $\quad$ Scientist1 $\quad$ Scientist2 $\quad$ Scientist3 $\quad$ Scientist4

Oregon. WI

\begin{tabular}{|c|c|c|c|c|c|}
\hline Total Area ${ }^{1}$ & 2,175 & 1,619 & 2,363 & 2,603 & 3,233 \\
\hline $\mathrm{Ca}^{2}$ & & .45 & .55 & .57 & .47 \\
\hline
\end{tabular}

Post Qak Mts. TX

$\begin{array}{lccccc}\text { Total Area } & 4,125 & 3,656 & 4,034 & 3,925 & 4,148 \\ \mathrm{Ca} & & .38 & .43 & .37 & .45\end{array}$

Madison, AL

$\begin{array}{lccccc}\text { Total Area } & 1,608 & 1,913 & 1,864 & 1,983 & 2,736 \\ \mathrm{Ca} & & .63 & .56 & .63 & .56\end{array}$

Farley, AL.

$\begin{array}{lccccc}\text { Total Area } & 5,794 & 6,305 & 5,438 & 5,979 & 5,985 \\ \mathrm{Ca} & & .80 & .77 & .82 & .82\end{array}$

West of Drinkwater Lake, CA

$\begin{array}{lccccc}\text { Total Area } & 5,587 & 5,260 & 5,362 & 5,614 & 6,499 \\ \mathrm{Ca} & & .82 & .81 & .84 & .79\end{array}$

${ }^{1}$ Area in hectares.

${ }^{2} \mathrm{Ca}=$ coefficient of areal correspondence. 


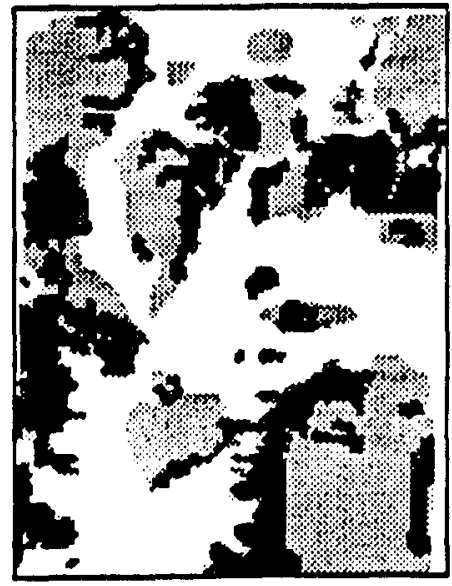

Scientist 1

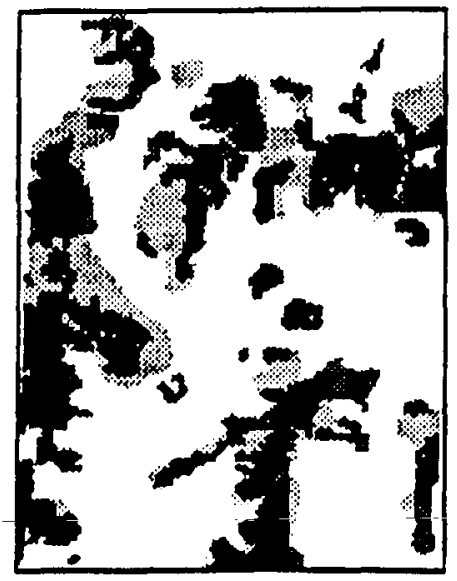

Scientist 3

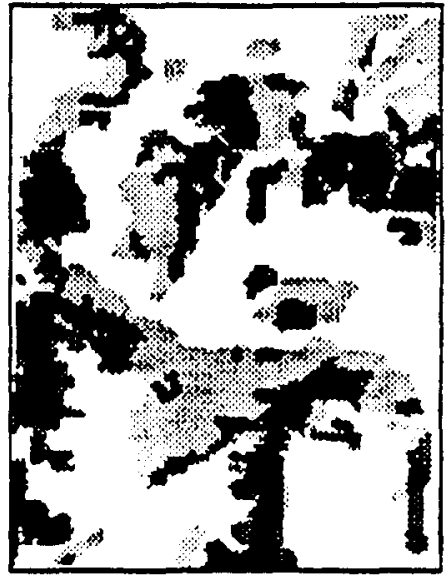

Scientist 2

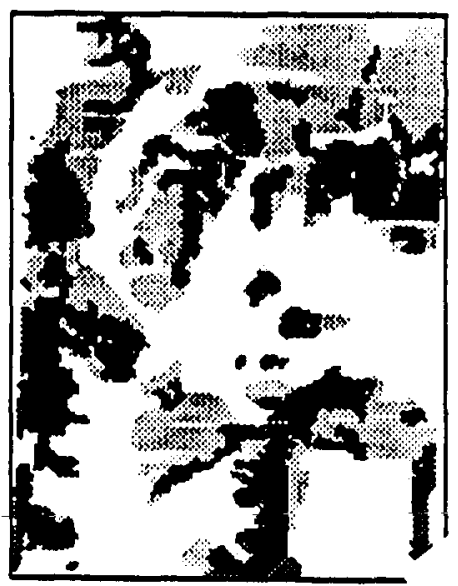

Scientist 4

Figure 20. Correspondence between All manually and automatically classified mounts for Oregon, Wisconsin. Manually classified mounts are in light gray, automatically classified mounts are in medium gray, and overlap is in dark gray. 


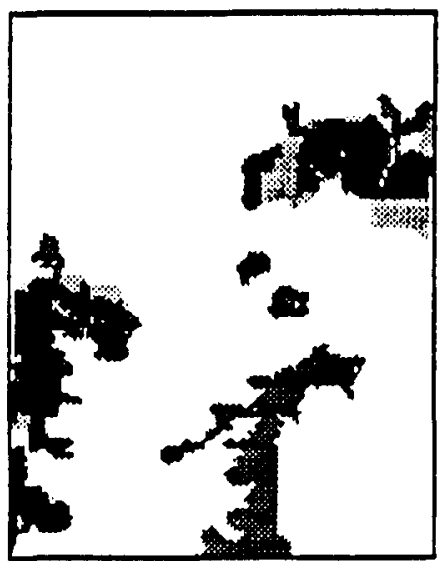

Scientist 1

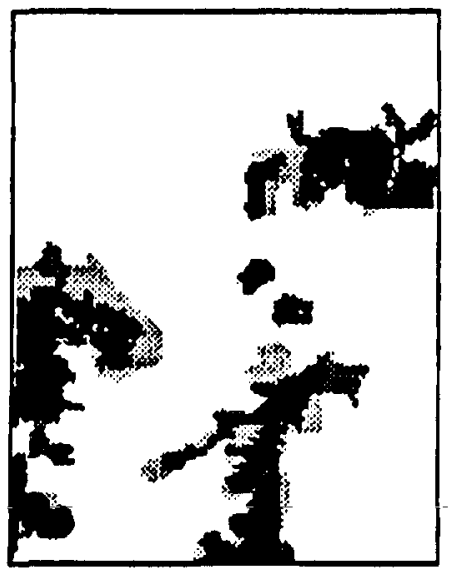

Scientist 3

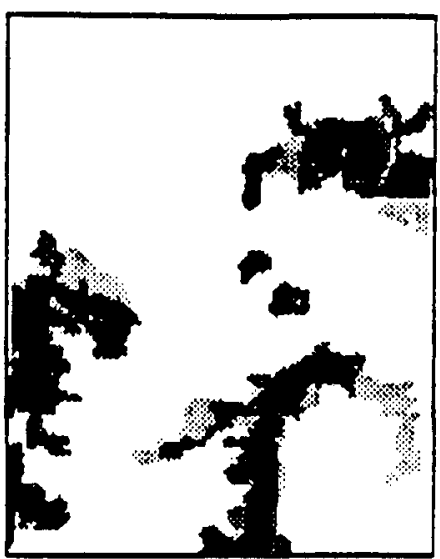

Scientist 2

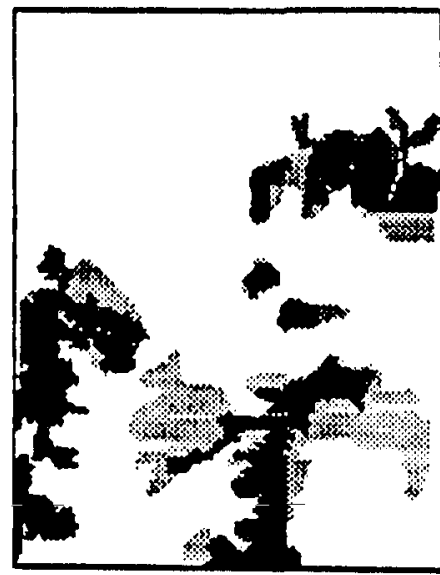

Scientist 4

Figure 21. Correspondence between manually and automatically classified Well-Defined mounts for Oregon, Wisconsin. Manually classified mounts are in light gray, automatically classified mounts are in medium gray, and overlap is in dark gray. 


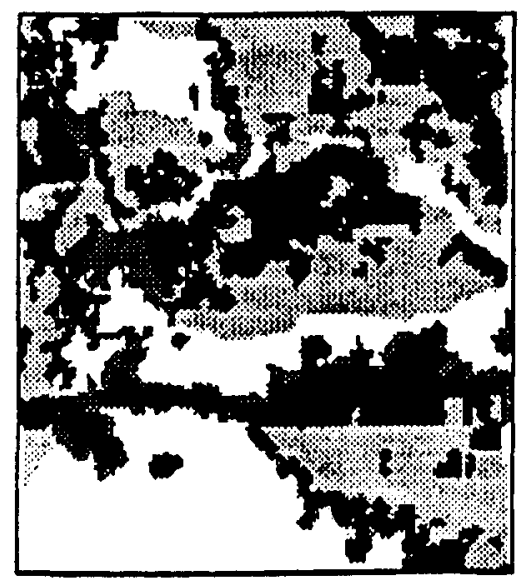

Scientist 1

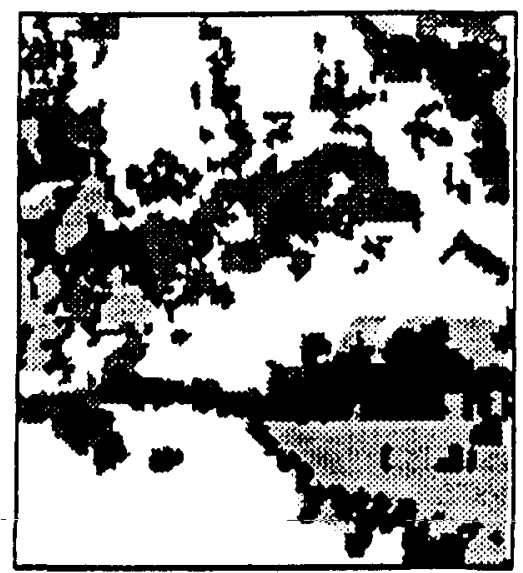

Scientist 3

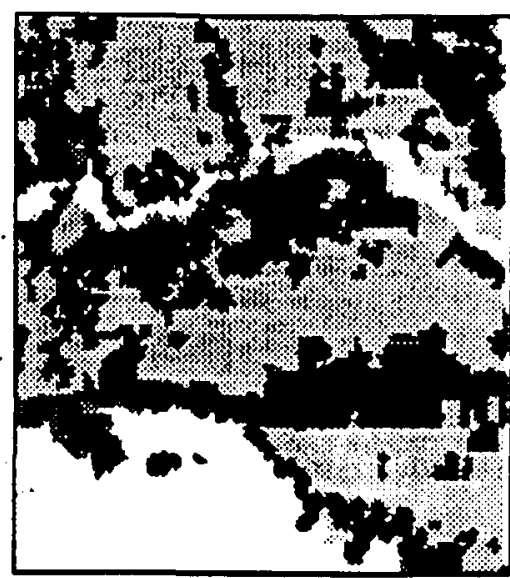

Scientist 2

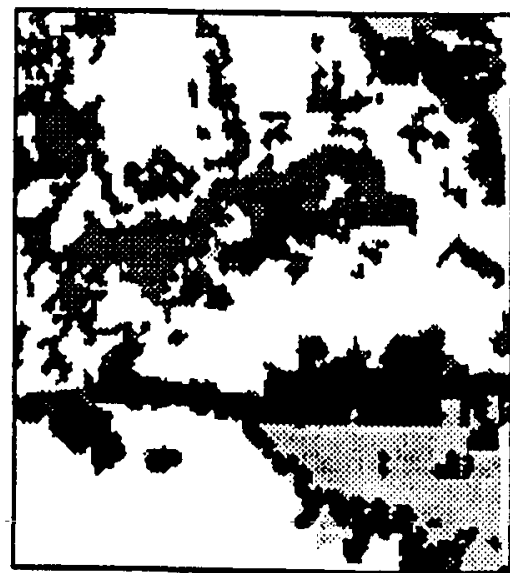

Scientist 4

Figure 22. Correspondence between All manually and automatically classified mounts for Post Oak Mountains, Texas. Manually classified mounts are in light gray, automatically classified mounts are in medium gray, and overlap is in dark gray. 


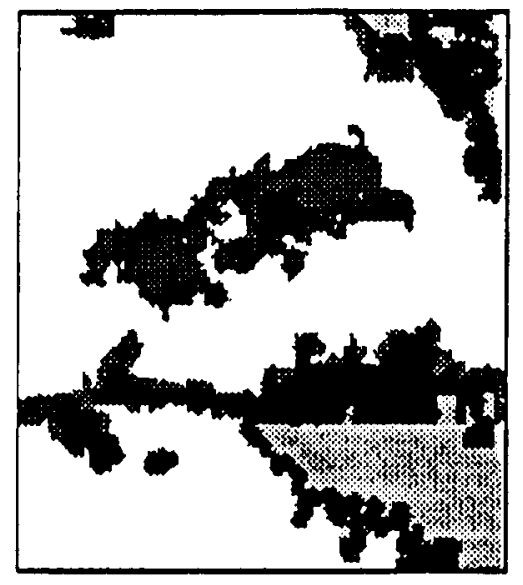

Scientist 1

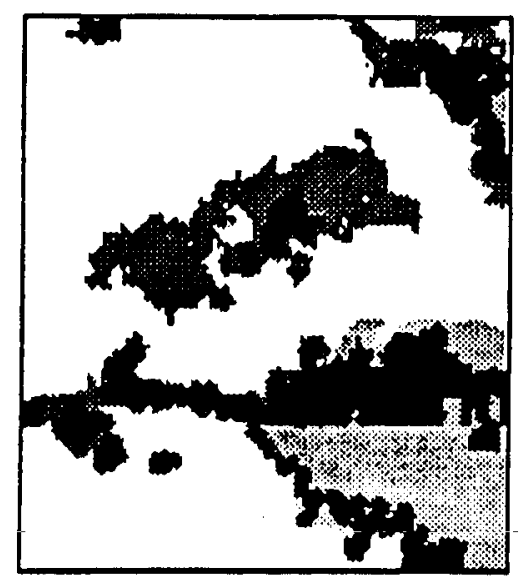

Scientist 3

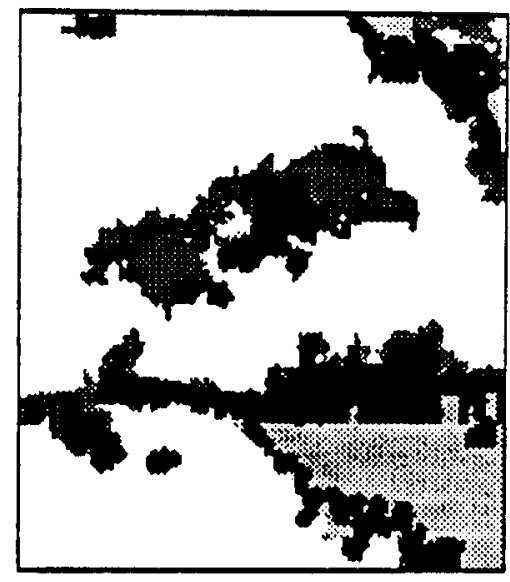

Scientist 2

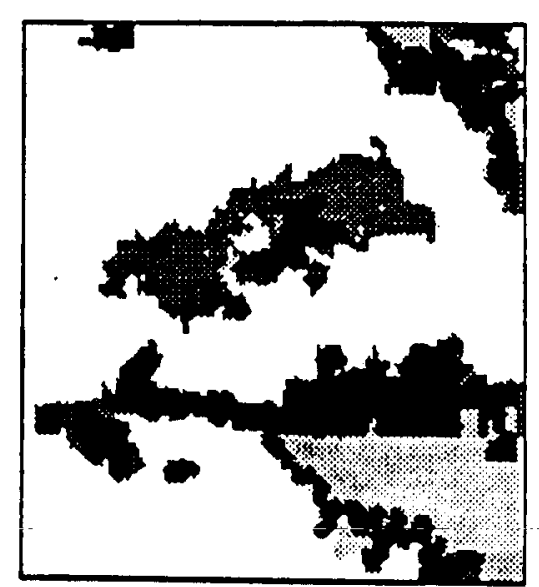

Scientist 4

Figure 23. Correspondence between manually and automatically classified Well-Defined mounts for Post Oak Mountains, Texas. Manually classified mounts are in light gray, automatically classified mounts are in medium gray, and overlap is in dark gray. 


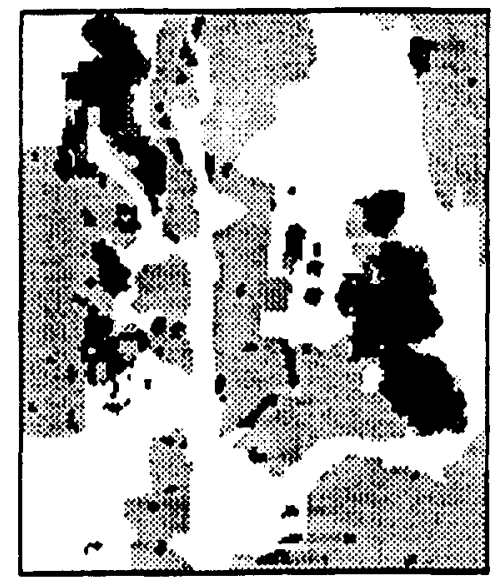

Scientist 1

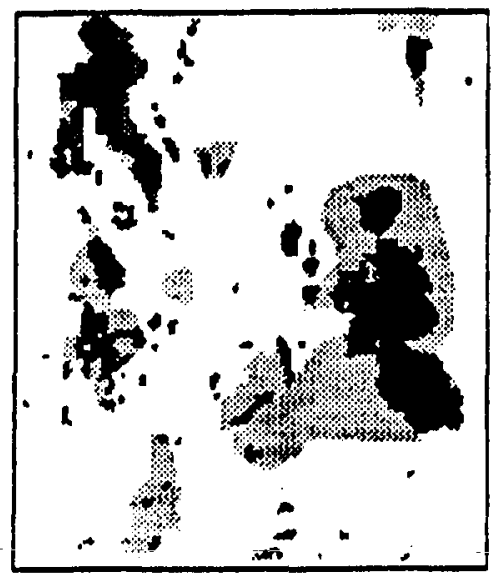

Scientist 3

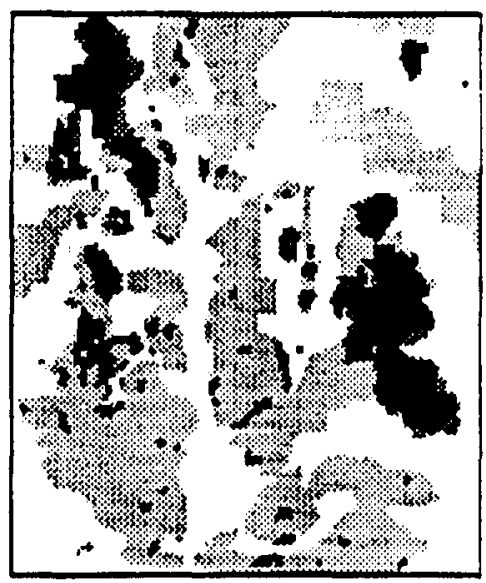

Scientist 2

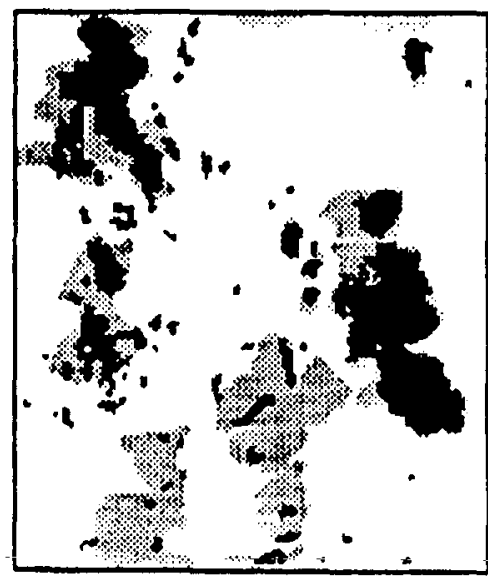

Scientist 4

Figure 24. Correspondence between All manually and automatically classified mounts for Madison, Alabama. Manually classified mounts are in light gray, automatically classified mounts are in medium gray, and overlap is in dark gray. 


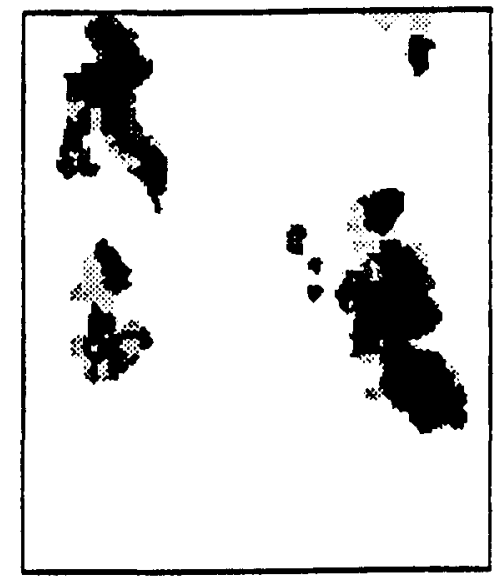

Scientist 1

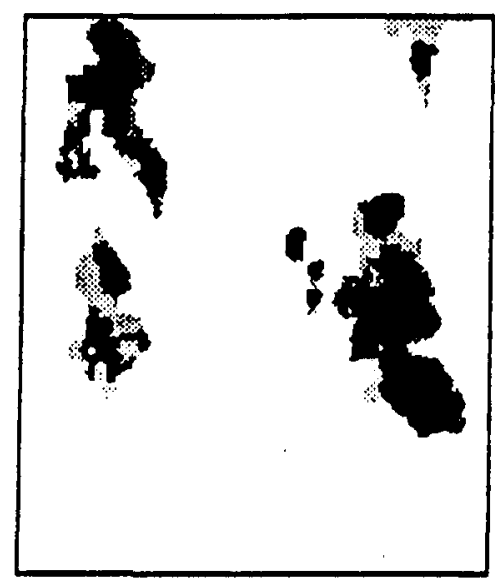

Scientist 3

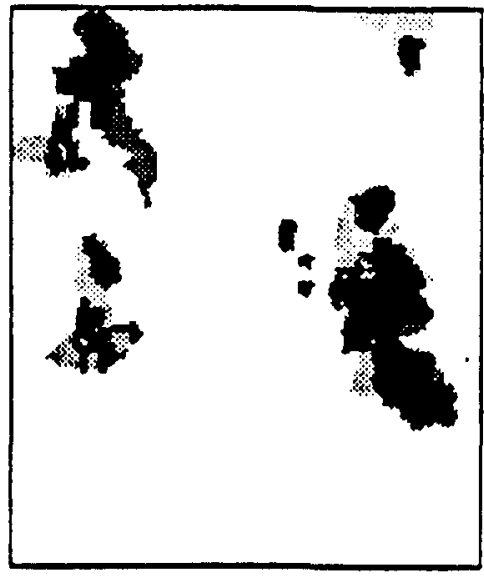

Scientist 2

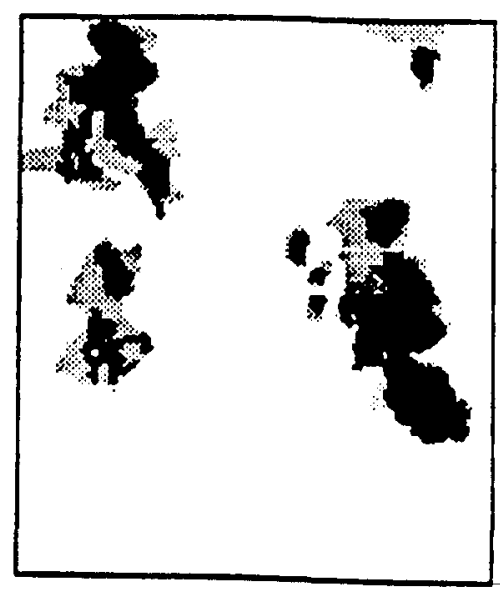

Scientist 4

Figure 25. Correspondence between manually and automatically classified Well-Defined mounts for Madison, Alabama. Manually classified mounts are in light gray, automatically classified mounts are in medium gray, and overlap is in dark gray. 
and others only extracted the high-relief features (Figures 28 and 29). When only the well-defined mounts are considered, the correspondences are high, ranging from 0.79 to 0.84 (Table 7 ).

\section{ANALYSIS}

This study attempts to simplify a complex and subjective classification problem by initially aggregating all terrain features into two major categories, mounts and non-mounts. A method was then developed to automatically partition digital elevation models into mount and non-mount areas.

It appears that this two-class approach to terrain classification is useful in some areas but not in others. The classification into mount and non-mount areas is most successful in moderate- or high-relief areas where the mounts are well-defined and have ridge points with the required slope characteristics. The classification does not work as well in low-relief areas or where the mount has a broad, relatively flat top, such as that present in the Post Oak Mountains, Texas, site or a narrow linear shape such as that near Gettysburg, Pennsylvania.

The results of the classification, however, are highly dependent on the developed method. For this reason, it is difficult to separate the usefulness of the classification scheme from the methods used to extract the mounts.

The developed method heavily relies on a universal approach, local neighborhood operators, and "critical values," such as the boundary slope between mount and non-mount. Each of these pose possible limitations to the current approach and will be addressed in turn.

First, application of a universal approach, which applies the same procedures to each DEM regardless of geographic location, may not be desirable. If the methods of mount identification can be tailored to the area covered by the DEM, it is possible that this classification would be useful in more areas than suggested by this research. However, it is likely that many areas require a much deeper model of terrain classification than the two-class approach used in this study.

Second, it appears that local neighborhood operators can provide valuable information, as a first look at the terrain. In many cases, however, a 3 by 3 window may be too small and restrictive for terrain features. Application of more regional operations, that examine the feature as a whole, may be required for accurate classification. This will become especially important when a specific classification is desired.

Finally, the results of this research suggest that a boundary slope exists between mount and non-mount. As used in this study, this "critical value" is a function of the local relief of the area. Further investigation with additional DEMs is required to determine if there is a unique local relief cut off relating to a slope boundary between mount and non-mount areas, or, if this too is dependent on the area under consideration. 


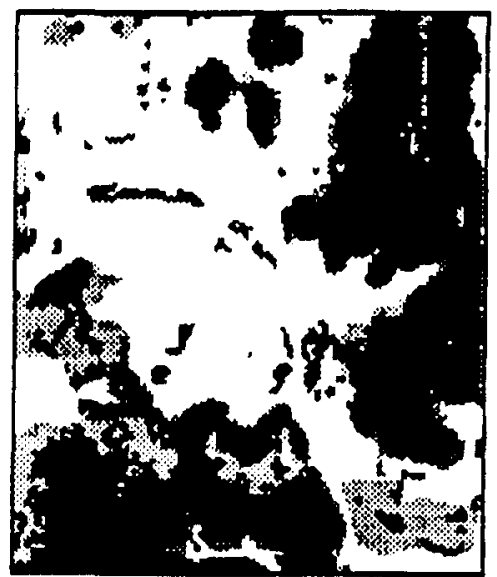

Scientist 1

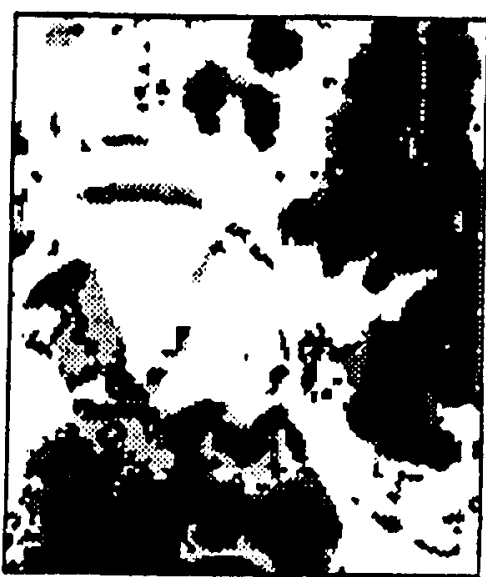

Scientist 3

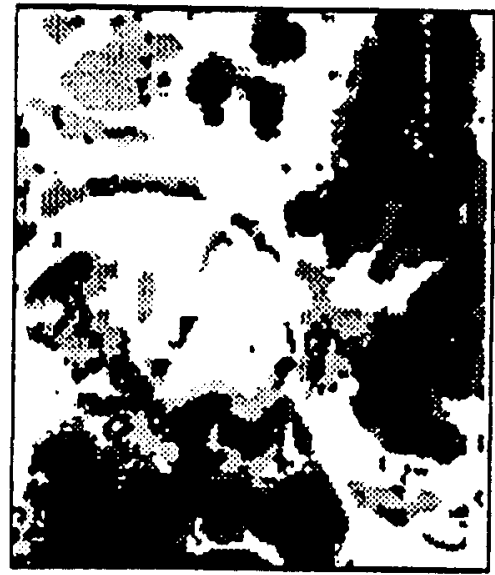

Scientist 2

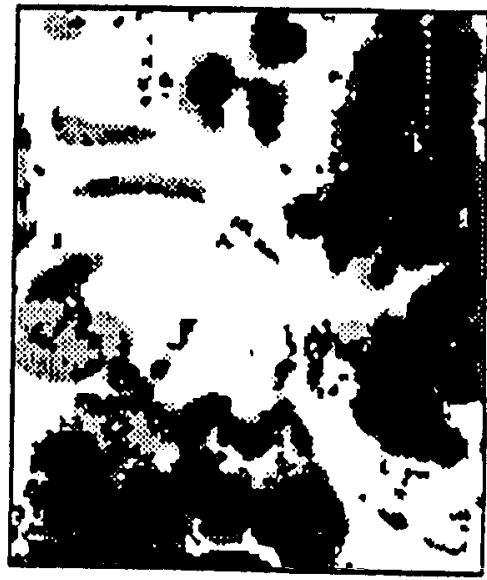

Scientist 4

Figure 26. Correspondence between All manually and automatically classified mounts for Farley, Alabama. Manually classified mounts are in light gray, automatically classified mounts are in medium gray, and overlap is in dark gray. 


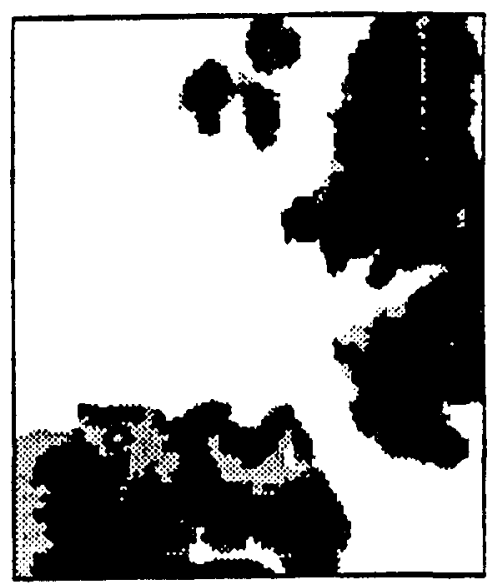

Scientist 1

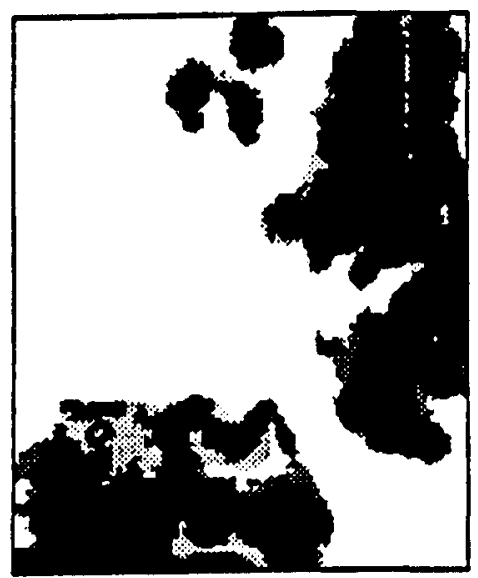

Scientist 3

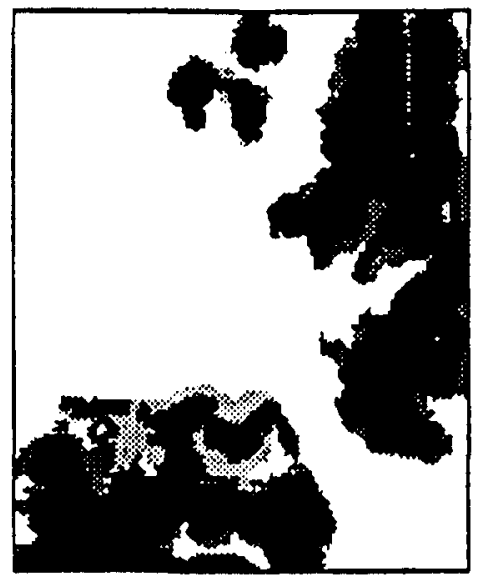

Scientist 2

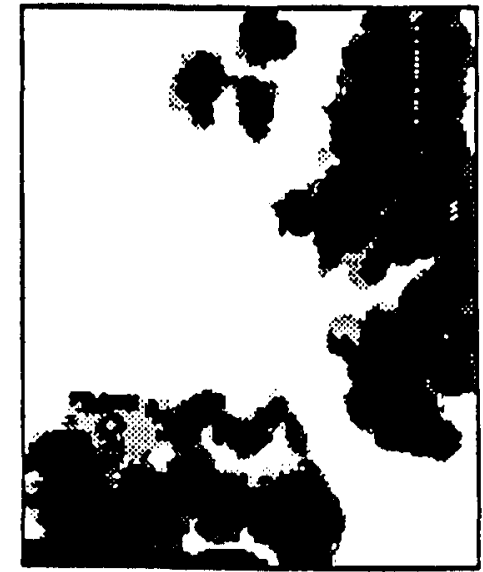

Scientist 4

Figure 27. Correspondence between manually and automatically classified Well-Defined mounts for Farley, Alabama. Manually classified mounts are in light gray, automatically classified mounts are in medium gray, and overlap is in dark gray. 


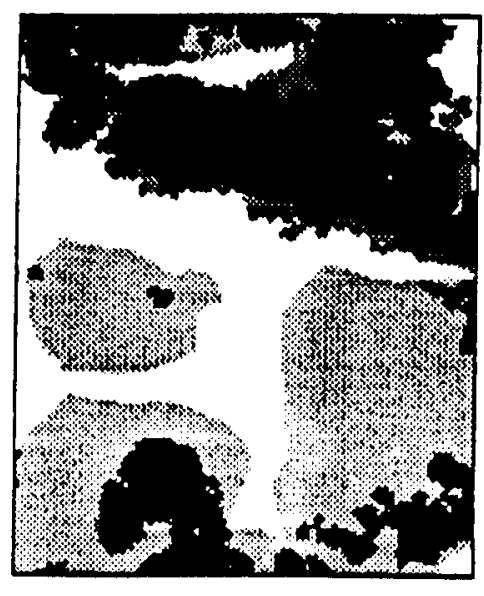

Scientist 1

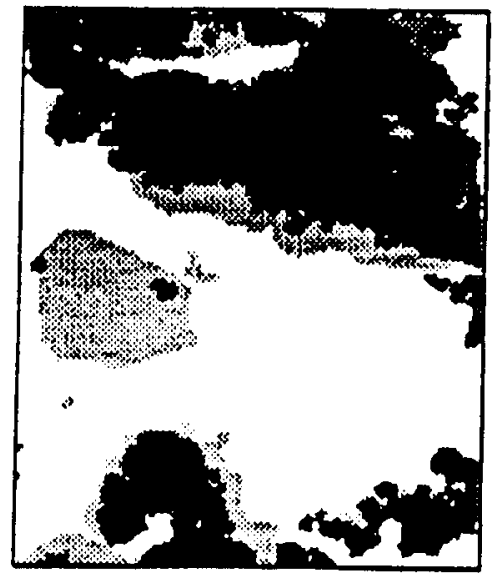

Scientist 3

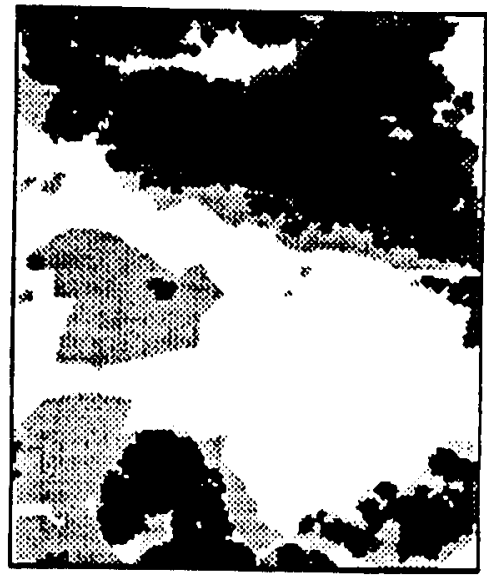

Scientist 2

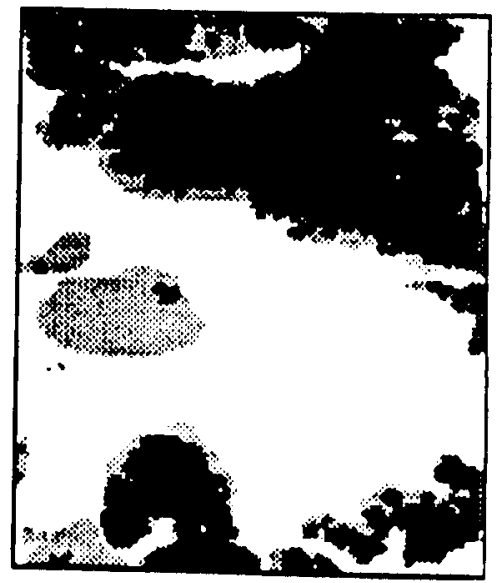

Scientist 4

Figure 28. Correspondence between All manually and automatically classified mounts for West of Drinkwater Lake, California. Manually classified mounts are in light gray, automatically classified mounts are in medium gray, and overlap is in dark gray. 


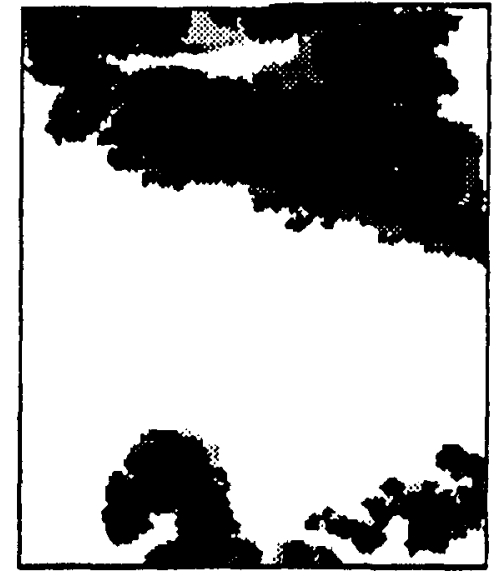

Scientist 1

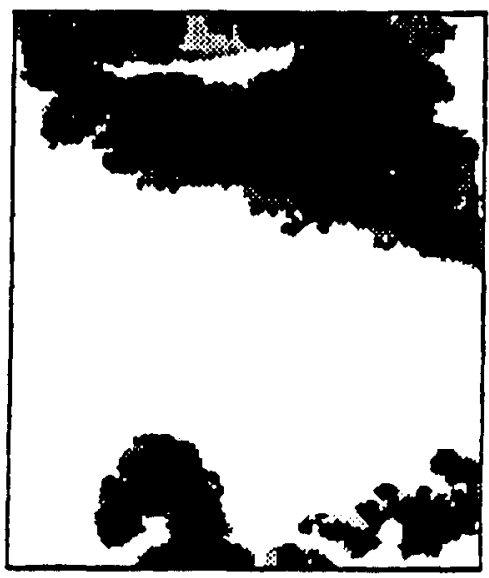

Scientist 3

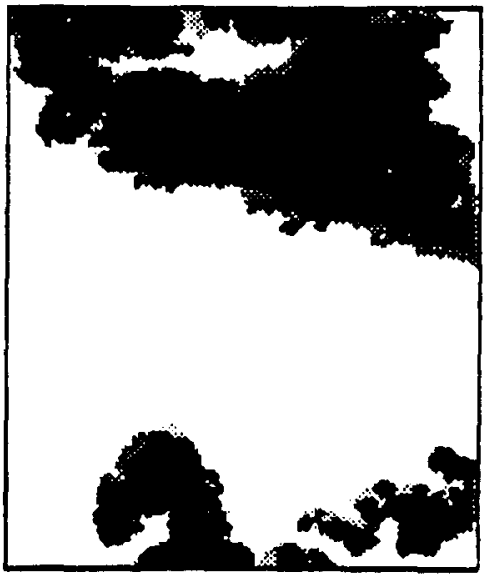

Scientist 2

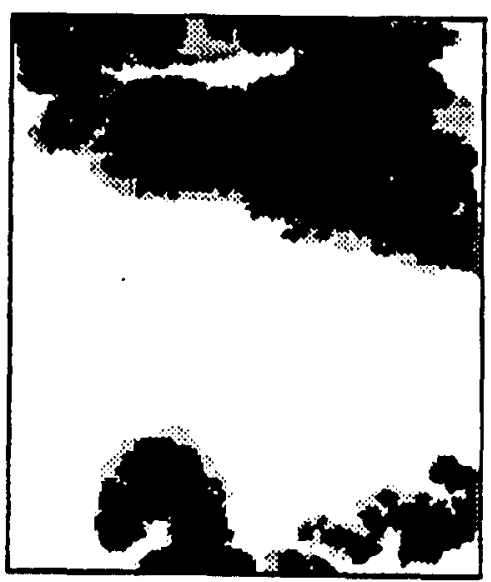

Scientist 4

Figure 29. Correspondence between manually and automatically classified Well-Defined mounts for West of Drinkwater Lake, California. Manually classified mounts are in light gray, automatically classified mounts are in medium gray, and overlap is in dark gray. 
Incorporation of knowledge-based procedures may help constrain and simplify the classification problem, reducing the limitations of the current approach. These procedures can include regional knowledge about the area, such as the physiographic region and climate, or local knowledge, such as vegetation and land-use. Relationships between knowledge, such as this, and terrain features have been studied by terrain analysts for many years. This knowledge can be used in a top-down approach to tailor the classification methods used in a certain area to the features that are expected to be present.

Examination of the 10 sites used in this research suggests that knowledge about the physiographic region of a DEM can be used to predict the success of the classification scheme and the developed method (Table 8). Physiographic regions (provinces) for each of the 10 DEMs were established using Fenneman's physical divisions of the United States $(1931,1938)$.

The developed method worked well on all the high-relief sites in the Basin and Range province - Mustang Mountains, Arizona; West of Drinkwater Lake, California; and Paradise Range, California. Mixed results were obtained for the three Alabama sites -- Madison, Farley, and Huntsville. These sites are located in the Interior Low Plateau and have moderate local relief.

Low correspondences, both overall and well-defined, were obtained for most of the sites in low-relief physiographic regions. These sites include Gettysburg, Pennsylvania, located in the Piedmont province; Oregon, Wisconsin, located in a glaciated portion of the Central Lowlands; and Post Oak Mountains, Texas, located in the Great Plains. However, the lowest relief site, Verona, Wisconsin, which also is located in the Central Lowlands, had moderate overall and well-defined correspondences.

In an attempt to understand the differences in correspondence between the two Wisconsin sites, the 7.5-minute topographic maps of Oregon and Verona (US Geological Survey 1982a, 1982b) were manually examined. The Oregon map shows many signs of continental glaciation, such as lakes, gravel pits, and linear ridges. The map of the Verona area, to the west, shows much less evidence of the erosional and depositional effects of glaciation. This area most likely lies in the transition zone between the glaciated portion of Wisconsin to the east and the driftless area to the west. This suggests that continental glaciation tends to blur the boundaries between mount and non-mount areas resulting in more poorly defined mounts and lower correspondences. Thus, knowledge regarding the geomorphic history of an area may also be used to tailor the classification methods.

Regional and local knowledge, such as that described above, could assist in the automatic classification of poorly defined mounts and other basic-level terrain features such as basins, plains, and flats. Once these features have been partitioned from the surrounding terrain, a more specific classification of the feature may be possible by applying operations tailored to the expected landforms.

Additional limitations to the current work may be imposed by the data source in terms of quality and resolution. Studies have shown that the data used in this study are sufficient for providing small-scale information to extract large terrain features, such as drainage basins, lakes and, in certain cases, mounts. However, it provides insufficient detail to extract detailed, local information, such as gully shape. Information such as this is frequently used by terrain analysts when performing a classification of a given area. 
Table 8

Relationship Between Sites, Physiographic Region and Correspondence of Automatic and Manual Classification

\begin{tabular}{|c|c|c|c|}
\hline Lecation & Physiographic Region & $\mathrm{Ca}^{1}$ & $\mathrm{Ca}^{2}$ \\
\hline Verona, WI & Central Lowlands & .65 & .68 \\
\hline Oregon, WI & Central Lowlands & $.38-.52$ & $.45-.57$ \\
\hline Gettysburg, PA & Piedmont & .26 & .58 \\
\hline Post Oak Mts, TX & Great Plains & $.37-.38$ & $.37-.45$ \\
\hline Madison, $\mathrm{AL}$ & Interior Low Plateau & $.18-.38$ & $.56-.63$ \\
\hline Farley, AL & Interior Low Plateau & $.63-.75$ & $.77-.82$ \\
\hline Huntsville, AL & Interior Low Plateau & .81 & .87 \\
\hline Mustang Mts, AZ & Basin and Range & .74 & .83 \\
\hline $\begin{array}{l}\text { West of Drinkwater } \\
\text { Lake, CA }\end{array}$ & Basin and Range & $.44-.71$ & $.79-.84$ \\
\hline Paradise Range, CA & Basin and Range & .81 & .82 \\
\hline $\begin{array}{l}{ }^{1} \mathrm{Ca}=\text { coefficient of } \\
\text { (individual value for }\end{array}$ & $\begin{array}{l}\text { ce for all mounts. } \\
\text { e for test sites) }\end{array}$ & & \\
\hline
\end{tabular}


It may be possible to extract information, such as gully shape, from higher quality and resolution data. However, until better data becomes readily available, it may be possible to extract similar detailed information, such as hydrography and vegetation, from other digital data sources. These sources can include US Geological Survey Digital Line Graph (DLG) data or Defense Mapping Agency Tactical Terrain Data (TTD), where available.

\section{CONCLUSIONS}

1. Manual terrain classification heavily relies on perception, learned skills and experience. To classify terrain features with computers, an attempt must be made to quantify the attributes associated with the chosen features.

2. This study simplifies the terrain classification process by employing a divide-and-conquer philosophy. Initially, the terrain is partitioned into two classes. These classes include mounts, which are considered to be elevated terrain features such as hills and mountains, and non-mounts.

3. This study suggests a method for automatically classifying mount and non-mount areas in a digital elevation model (DEM). Performance of the developed method is compared to results obtained by a manual classification of synthetic stereo images generated from the same DEM.

4. The results suggest that, using the developed method, mount is a useful classification in moderate or high-relief areas where the mounts are well-defined, i.e., they are easily distinguished from the non-mount areas by a sharp break in slope.

5. These procedures do not work as well where the mounts are poorly defined, have extensive low-slope tops, and/or do not have ridge points with the required slope. The variability among the scientists for the test sites suggests that manual classification of poorly defined mounts is also more difficult than the classification of well-defined mounts using elevation data alone.

6. Limitations of the current method, due to reliance on a universal approach, local neighborhood operators and critical values, may be minimized by incorporating knowledge-based procedures to constrain and simplify the classification problem. These procedures could include regional knowledge about the area, such as the physiographic region or climate.

7. Results of the study suggest that a relationship exists between the physiographic region of the DEM and the success of the developed method. The method had good success in high-relief physiographic regions and poor results in low-relief regions. Knowledge such as this could be used to develop local classification procedures that attempt to identify different types of features based on those expected to be present in a particular region.

8. Other local knowledge, such as that used in manual terrain classification, could also be incorporated into an automated terrain classification system in order to assist in feature identification. This knowledge could include such things as vegetation, drainage, and land-use where they are available in digital form. 
9. Regional and local knowledge, such as that described above, could assist in the automatic classification of other basic-level terrain features, such as basins, plains, and flats, as well as more specific subordinate-level geomorphologic landforms.

10. Limitations to the current study are also imposed by the resolution and quality of the data source; however, many military systems will have to rely on DMA standard products which have similar resolution and quality. 


\section{BIBLIOGRAPHY}

Band, Lawrence E., 1986. "Topographic Partition of Watersheds with Digital Elevation Models," Water Resources Research, Vol. 22, No. 1, pp. 15-24.

Batson, R.M., K. Edwards and E.M Eliason, 1976. "Synthetic Stereo and LANDSAT Pictures," Photogrammetric Engineering and Remote Sensing, Vol. 42, No. 10, pp. 1279-1284.

Dikau, R., 1989. Three Dimensional Applications in Geographical Information Systems, In J. Raper, (ed.), Taylor \& Francis, London, pp. 51-77.

Evans, I.S., 1972. "General Geomorphometry, Derivatives of Altitude, and Descriptive Statistics," In R.J. Chorley, (ed.), Spatial Analysis in Geomorphology, Harper \& Row, Publishers, NY, pp. 17-90.

, 1987. "The Morphometry of Specific Landforms," in V. Gardiner (ed.), Proceedings. First International Conference on Geomorphology 1986, Part II, pp. 105-124.

Fenneman, N.M., 1931. Physiography of the Western United States, McGraw-Hill Book Company, Inc., $N Y$.

, 1938. Physiography of the Eastern United States, McGraw-Hill Book Company, Inc., NY.

Frank, A.U, B. Palmer and V.B. Robinson, 1986. "Formal Methods for Accurate Definition of Some Fundamental Terms in Physical Geography," Proceedings. Second International Symposium on Spatial Data Handling, Seattle, WA, pp. 583-599.

Graff, L.H., 1991. Automated Classification of Basic-LevelTerrain Features In Digital Elevation Models, Unpublished M.S. Thesis, Department of Geography, University of WisconsinMadison, Madison, WI, 192 p.

Guptill, S.C., K.J. Boyko, M.A. Domaratz, R.G. Fegeas, H.J. Rossmeissl, and E.L. Usery, 1990. "An Enhanced Digital Line Graph Design," United States Geological Survey Circular 1048, United States Geological Survey, Reston, VA.

Hoffman, R.R., 1985. What Is A Hill? An Analysis of the Meaning of Topographic Terms, ETL Report No. 0576, U.S. Army Engineer Topographic Laboratories, Ft. Belvoir, VA.

Hunt, C.B., 1967. Physiography of the United States, W.H. Freeman \& Company, NY.

Jenson, S.K., 1985. "Automated Derivation of Hydrologic Basin Characteristics from Digital Elevation Model Data," Proceedings, Auto Carte 7, Washington, DC, pp. 301-310.

and J.O. Dominque, 1988. "Extracting Topographic Structure from Digital Elevation Data for Geographic Information Systems Analysis," Photogrammetric Engineering and Remote Sensing, Vol. 54, No. 11, pp. 1593-1600. 
Jolicoeur, P., M.A. Gluck and S.M. Kosslyn, 1984. "Pictures and Names: Making the Connection," Cognitive Psychology, Vol. 16, pp. 243-275.

Lakoff, G., 1987. Women. Fire, and Dangerous Things: What Categories Reveal About the Mind, The University of Chicago Press, Chicago, IL.

Lay, J.G., 1991. "Terrain Feature Extraction From Digital Elevation Models: A Multi-Perspective Exploration," Proceedings, ACSM Technical Meeting, Atlanta, Georgia, pp. 191-199.

Mark, D.M., 1975. "Geomorphometric Parameters: A Review and Evaluation," Geografiska Annaler, Vol. 57 A, No. 3-4, pp. 165-177.

Mintzer, O. and J. Messmore, 1984. Terrain Analysis Procedural Guide for Surface Configuration, U.S. Army Corps of Engineers, Engineer Topographic Laboratories, ETL-0352, Fort Belvoir, VA.

Pike, R.J., 1988. "Toward Geometric Signatures for Geographic Information Systems, " Proceedings, International Symposium on GIS (IGIS 1987), Vol. 3, pp. 15-26. and G.P. Thelin, 1989. "Cartographic Analysis of U.S. Topography from Digital Data," Proceedings, Auto-Carto 9, pp. 631-640.

Peucker, T.K. and D.H. Douglas, 1975. "Detection of Surface-Specific Points by Local Parallel Processing of Discrete Terrain Elevation Data," Computer Graphics and Image Processing, Vol. 4, pp. 375-387.

Rinker, J.N., 1972. "Slope," In Group Procedures Relevant to the Analysis and Interpretation of Remote Sensing Imagery, In-House Report, U.S. Army Engineer Topographic Laboratories, Fort Belvoir, VA.

Rives, J.M. and G.A. Besaw, 1990. Automated Terrain Inference From Digital Elevation Data, Final Technical Report, U.S. Army Communication-Electronics Command, Fort Monmouth, NJ.

Rosch, E., C.B. Mervis, W.D. Gray, D.M. Johnson, and P. Boyes-Braem, 1976. "Basic Objects in Natural Categories," Cognitive Psychology, Vol. 8, pp. 382-439.

Rosch, E., 1978. "Principles of Categorization," Cognition and Categorization, In E. Rosch and B.B. Lloyd, (eds.), Halstead Press, NY, pp. 27-48.

Seemuller, W.W., 1989. "The Extraction of Ordered Vector Drainage Networks from Elevation Data," Computer Vision. Graphics, and Image Processing. Vol. 47, pp. 45-58.

Unwin, D., 1981. Introductory Spatial Analysis, Methuen \& Co. Ltd., New York, NY. 
U.S. Geological Survey, 1982a. "Oregon, Wisconsin," 7.5-minute Topographic Map Series 425230N,892230W/7.5, DMA 3169 IV NW - Series V861, US Geological Survey, Reston, VA.

, 1982b. "Verona, Wisconsin," 7.5-minute Topographic Map Series 425230N,8930W/7.5, DMA 3069 I NE - Series V861, US Geological Survey, Reston, VA. , 1990. Digital Elevation Data,Data Users Guide 5, National Mapping Program, Reston, VA.

Way, D.S., 1973. Terrain Analysis, Dowden, Hutchinson \& Ross, Inc., Stroudsburg, PA. 